\title{
A Novel Human Membrane Protein Interacting with the Short Fiber of Enteric Adenovirus
}

\author{
Anne-Laure Favier, ${ }^{1,2}$ Renata Grzela, ${ }^{1,3}$ Siergiej Tcherniuk, \\ Marianna Charlotte Harsi, ${ }^{1,5}$ and Jadwiga Chroboczek ${ }^{1,3,6}$ \\ ${ }^{1}$ Institut de Biologie StructuraleJean-Pierre Ebel, 41, rue Jules Horowitz, 38027 Grenoble Cedex 1, France \\ ${ }^{2}$ IRBA-CRSSA, Unité de Virologie, 38702 La Tronche, France \\ ${ }^{3}$ Institute of Biochemistry and Biophysics, Polish Academy of Sciences,Pawinskiego 5a, 02106 Warszawa, Poland \\ ${ }^{4}$ CRBM, Universote Montpellier 1, 34293 Montpellier, France \\ ${ }^{5}$ Departmentof Microbiology, Biomedical Sciences Institute, University of Sao Paulo, 05508-900 Sao Paulo, SP, Brazil \\ ${ }^{6}$ TheREx,TIMC-IMAG, UMR 5525, CNRS/UJF, Domaine de La Merci, 38700 La Tronche, France
}

Correspondence should be addressed to Jadwiga Chroboczek; jadwiga.chroboczek@imag.fr

Received 11 October 2012; Accepted 30 October 2012

Academic Editors: A. Berdis, A. Kajon, N. Maneekarn, and J. Tozser

Copyright (C) 2013 Anne-Laure Favier et al. This is an open access article distributed under the Creative Commons Attribution License, which permits unrestricted use, distribution, and reproduction in any medium, provided the original work is properly cited.

\begin{abstract}
Human enteric adenoviruses of species F, HAdV-40 and HAdV-41 (Ad40 and Ad41), are associated with gastroenteritis in children. Ad attachment to the primary receptor on the cell surface is mediated by the distal head domain of the fiber protein, an antenna-like component of the adenovirus capsid. Differently from the majority of human Ads that possess one type of fiber on their capsid, the Ad40 and 41 have two distinct fibers. The long fiber recognizes the host membrane protein CAR, which permits virus attachment, but nothing is known about the role of the short fiber. Using the head domain of the Ad41 short fiber, we fished out a putative membrane protein that has never been previously described. This partner of the short fiber of enteric Ad41 (ParAd41) is a small, hydrophobic protein with three putative trans membrane domains, which interacts with the Ad41 short fiber but not with the Ad41 long fiber or with the fiber of respiratory Ad2 serotype. ParAd41 is localized in intracellular membranes including the nuclear membrane. Saturation of the short fiber with ParAd41 inhibits virus infectivity, which substantiates the putative role of ParAd41 in enteric Ads tropism. It is conceivable that the interaction of the short fiber with ParAd41 mediates virus postattachment endocytosis step as well as interaction with the nuclear membrane prior to the injection of viral DNA into the nucleus, thus enabling enteric adenovirus infection. This study is the first one to probe the molecular nature of enteric Ad41 tropism.
\end{abstract}

\section{Introduction}

Adenovirus (Ad) is a medium-sized nonenveloped DNA virus causing mild respiratory and more serious infantile gastrointestinal infections. The recent revival of the interest in adenoviruses stems from their unmatched efficacy in heterologous gene transfer during gene therapy applications. Ad has an icosahedral capsid built from three major proteins; the virion facets are made of trimeric hexons whereas capping vertices are composed of pentameric penton bases noncovalently linked to the outward pointing trimeric fibers.

The component of adenovirus capsid that is involved in virus cell entry is the penton, a complex of penton base anchored in the viral capsid together with antenna-like fiber attached to it. The C-terminal globular head domain of the fiber recognizes the attachment receptor [1-3]. Several fiber attachment receptors have been identified. For Ad species A, $\mathrm{C}, \mathrm{D}, \mathrm{E}$, and the long fiber of species $\mathrm{F}$, the coxsackievirusadenovirus receptor (CAR) is the main attachment protein [4]. Ad37 of species D has been reported to use sialic acid instead of CAR as a cellular receptor [5]. CD46 has been proposed as the receptor for some Ads of species B (such as Ad16 and Ad35) [6]. Recently, the receptor for other Ads of species $B$, serotypes $3,7,11$, and 14 , has been identified to be desmoglein 2, a transmembrane glycoprotein belonging to the cadherin protein family [7]. 
Human enteric adenoviruses of species F, HAdV-40 and HAdV-41 (Ad40 and Ad41), are associated with gastroenteritis in children $[8,9]$. While the majority of human Ads have one kind of fiber, these enteric serotypes possess two fibers of different lengths and primary sequence, present in the capsid in equimolar amounts (10-12). Similar to fibers of several other serotypes, the long fiber of the Ad40/41 interacts with cellular tight junctions' component CAR [4]. This interaction, in view of the ubiquitous tissue distribution of CAR, cannot account for the narrow tropism of enteric Ads for the gastrointestinal tract (GI). We hypothesized that the short fiber might have specific partners in the host cells, the study of which could help to elucidate the role of the short fiber in enteric Ad tropism and also possibly in its life cycle. To search for such protein partners, we used the doublehybrid system, with the head domain of Ad41 short fiber incorporated in the bait. Several human proteins have been "fished out," one of them a putative membrane protein that has never been described previously. This paper describes the properties of this protein named Partner of the enteric Ad41 short fiber (ParAd41) ParAd41 sequence (clone 28) has an EMBL accession no. AF343342.

\section{Materials and Methods}

2.1. Virus and Viral Proteins. Ad41 strain Tak was propagated in the 293 cell line according to [10] and the resulting titer of $10^{9} \mathrm{FFU} / \mathrm{mL}$ was measured by fluorescent focus assay. For saturation curve, 293 cells were seeded at a density of $3 \times$ $10^{4}$ cells per well in 96-well plates, so that infection could be done after two days at $90 \%$ confluence. The saturation curve was obtained as described in [10]. Ad5.SF40Luc and Ad5.LF40Luc, a kind gift of M. Havenga (Crucell), are recombinant Ad5 bearing long or short fiber of enteric Ad40 virus and able to express the luciferase protein. The recombinant Ad2Luc able to express luciferase was prepared in the laboratory.

The Ad5 fiber was purified from the part of the initial $\mathrm{CsCl}$ gradient centrifugation localized above the virus band [7]. The mixture of viral proteins was dialyzed against $20 \mathrm{mM}$ Tris and $1 \mathrm{mM}$ EDTA, $\mathrm{pH} 7.5$, and chromatographed on a Q-Sepharose column, with fiber protein eluted at approximately $0.15 \mathrm{M} \mathrm{NaCl}$. Pooled fiber protein fractions were dialyzed against $40 \mathrm{mM}$ MES and $1 \mathrm{mM}$ EDTA, $\mathrm{pH}$ 5, and applied to a S-Sepharose column from which fiber protein was eluted with $0.15 \mathrm{M} \mathrm{NaCl}$. Purification was monitored by Western blotting, with Ad5 fiber detected with antiAd3 fiber-dodecahedron (DFAd3) antibody (prepared in the laboratory) diluted at $1: 50000$.

Native Ad41 proteins were obtained from Ad41-infected 293 cells grown in monolayers. The supernatant above the virus band in the first $\mathrm{CsCl}$ gradient centrifugation was dialyzed against $40 \mathrm{mM}$ MES/1 mM EDTA, pH 6.1, and centrifuged at $15000 \mathrm{rpm}$ for $15 \mathrm{~min}$ [10]. Fractions containing either long or short pentons, identified by fiber mobility in SDS-PAGE, were pooled, concentrated with Centricon $30 \mathrm{~K}$, and applied to a Superose 12 column (Pharmacia), which was developed with $40 \mathrm{mM}$ MES/1 mM EDTA, pH 6.1, containing $200 \mathrm{mM} \mathrm{NaCl}$. Fractions containing fiber protein were detected by Western blotting with the monoclonal antibody 4D2 (Abcam ab3233), which recognizes the $\mathrm{N}$ terminal fiber epitope. Purified proteins were quantified with the Bradford kit (Bio-Rad).

2.2. Yeast Two-Hybrid System. For bait construction, a fragment of the Ad41 strain Tak genome, corresponding to the C-terminal head domain of the short fiber (HSF41) flanked by NcoI and BamHI sites, was PCR-cloned into pCR-Script $\mathrm{SK}(+)$ (Stratagene), using the upstream $5^{\prime}$-GCGCCATGGAGCTTAACGTTAAGTTGGGA-3' and downstream $5^{\prime}$-CGCGGATCCTTTATTGTTCAGTTATGTAGC- $3^{\prime}$ primers. The head domain gene excised with NcoI and BamHI was inserted into the vector pAS2-1 (Clontech) in frame with the DNA-binding domain of GAL4 (residues 1-147 of BD). The resulting plasmid pAS-HSF41 expresses the C-terminal head domain of the short fiber (residues L199-Q387, EMBL accession no. X17016), in Cterminal fusion with $\mathrm{BD}$. The same procedure was used to generate the pAS-HLF41, using upstream $5^{\prime}$-GGAAACCATGGCACTAGTTGTTAAGCTTGGG-3' and downstream $5^{\prime}$-GCGCGGATCCTTTATTGTTCTGTTACATA$3^{\prime}$ primers, to express the C-terminal head domain of the Ad41 long fiber (residues L360-Q562, Swiss Prot accession no. P14267) in C-terminal fusion with BD. The human embryonic kidney cDNA library (Clontech HL4031AH), containing $2.5 \times 10^{6}$ different cDNA clones inserted into the pACT2 vector in frame with GAL4-AD (AD), was screened with the fusion protein BD-HSF41 as a bait, as described in the Clontech Manual.

2.3. Recombinant ParAd41 and Anti-ParAd41 Antibody. For expression in bacteria, the ParAd41 gene was synthesized by PCR, using the appropriate two-hybrid library clone as template and primers $5^{\prime}$-CGCGGTACCTATCATGGAGACTTTGTAC-3' and $5^{\prime}$-GTGAACTTGCGGGGTTTTTCAGTATCTACGAT-3' and cloned into pET30b (Novagen). The construct was confirmed by DNA sequencing.

The His-tagged ParAd41 was expressed in BL21 Codon Plus (DE3)-RP strain (Stratagene), after induction with $0.4 \mathrm{mM}$ IPTG at $30^{\circ} \mathrm{C}$ for $4 \mathrm{~h}$. After cell lysis in the absence of detergent, the recombinant protein was recovered in the pellet. The effect of detergent on protein solubility was assayed as follows. The pellet was rinsed with $20 \mathrm{mM}$ Tris/ $150 \mathrm{mM} \mathrm{NaCl}$ buffer, pH 7.5, containing a cocktail of protease inhibitors and suspended in buffer with CHAPS or Triton X-100 added at $4^{\circ} \mathrm{C}$ to a final concentration of $1 \%(\mathrm{w} / \mathrm{v})$. The pellet was frozen and thawed three times and incubated on ice for $5 \mathrm{~min}$. Supernatant and pellet were separated by centrifugation for $10 \mathrm{~min}$ at $13000 \mathrm{rpm}$. Analysis by Western blot showed better solubility of ParAd41 in Triton X-100 than in CHAPs. Therefore, soluble ParAd41 was obtained as follows. Cells were lysed by three cycles of freezing and thawing followed by sonication in Tris buffer, $\mathrm{pH} 7.5$, containing $150 \mathrm{mM} \mathrm{NaCl}$, $1 \%$ Triton X-100, $50 \mathrm{ng} / \mathrm{mL}$ DNase (Sigma), and complete EDTA-free protease inhibitor cocktail (Roche). The protein extract was centrifuged at $18000 \mathrm{rpm}$ for $20 \mathrm{~min}$ and the 
protein was purified on a nickel column (Bio-Rad) with elution by $50-100 \mathrm{mM}$ imidazolee in buffer $\mathrm{A}$.

For affinity purification of the antibody, ParAd41 was purified under denaturing conditions. Bacterial pellet obtained from $1 \mathrm{~L}$ culture bearing plasmid pET30bParAd was suspended in $20 \mathrm{~mL}$ lysis buffer $(10 \mathrm{mM}$ Tris, $\mathrm{pH} 8$, $100 \mathrm{mM} \mathrm{NaH}_{2} \mathrm{PO}_{4}$, and $8 \mathrm{M}$ urea). The soluble fraction was incubated with $1 \mathrm{~mL}$ of Ni-NTA agarose beads (Qiagen) equilibrated with lysis buffer for $1 \mathrm{~h}$ at room temperature. The unbound fraction was removed and the beads were washed once with $5 \mathrm{~mL}$ of lysis buffer and twice with $5 \mathrm{~mL}$ of $10 \mathrm{mM}$ Tris buffer, $\mathrm{pH} 6.3$, containing $100 \mathrm{mM} \mathrm{NaH}_{2} \mathrm{PO}_{4}$ and $8 \mathrm{M}$ urea. Bound proteins were eluted with five $500 \mu \mathrm{L}$ portions of $10 \mathrm{mM}$ Tris buffer, $\mathrm{pH} 4.5$, containing $100 \mathrm{mM}$ $\mathrm{NaH}_{2} \mathrm{PO}_{4}$ and $8 \mathrm{M}$ urea. All fractions were analyzed by Western blotting with crude anti-ParAd41 serum. Fractions containing the protein of interest were mixed with $500 \mu \mathrm{L}$ $\mathrm{Ni}^{2+}$ beads and dialyzed against $20 \mathrm{mM}$ Tris buffer, $\mathrm{pH}$ 7.5 , containing $150 \mathrm{mM} \mathrm{NaCl}$ (buffer A) and decreasing concentration of urea $(6 \mathrm{M}, 4 \mathrm{M}, 2 \mathrm{M}, 1 \mathrm{M})$, followed by final dialysis against three changes of buffer A containing only $1 \%$ Triton X-100. Change in $\mathrm{pH}$ from 4.5 to 7.5 caused binding of the protein to the beads. The $\mathrm{Ni}^{2+}$ beads were washed with $20 \mathrm{mM}$ imidazole in buffer A containing 1\% Triton $\mathrm{X}-100$. After the last dialysis, the ParAd41 was extracted from the beads with $250 \mathrm{mM}$ imidazole in buffer A/Triton $\mathrm{X}-100$. The protein was diluted fourfold with buffer A and concentrated threefold by centrifugation through Microcon YM-10 (Millipore), with simultaneous removal of imidazole and Triton X-100.

Anti-ParAd41 serum was produced in rabbits (ESD, France) using as antigen the E. coli-expressed protein extracted from 15\% SDS-PAGE gel. For use in confocal microscopy, the antibody was purified on $\mathrm{CNBr}$-Sepharose 4B (Amersham Biosciences) containing covalently attached ParAd41, purified as above. Antibody purification was performed according to the manufacturer's recommendations. CNBr-Sepharose with bound ParAd41 was washed with PBS and incubated with anti-ParAd41 serum overnight at $4^{\circ} \mathrm{C}$. Unbound antibody was removed by washing with PBS. Bound anti-ParAd41 antibody was eluted with $100 \mathrm{mM}$ glycine, $\mathrm{pH}$ 2.4, and immediately neutralized with $3 \mathrm{M}$ Tris buffer, $\mathrm{pH} 8.8$ (30 $\mu \mathrm{L}$ per $1 \mathrm{~mL}$ of eluate).

2.4. Western Blot Analysis. Proteins were electrotransferred onto PVDF membrane (Millipore), and after blocking the membrane with TBS/Tween/5\% defatted milk for $1 \mathrm{~h}$, it was incubated with the appropriate antibody using the ECL detection system (Amersham). Anti-His antibody (Sigma) and anti-ParAd41 were used at dilutions $1: 2500$ and $1: 5000$, respectively.

2.5. Sequence Analysis. CBI-Blast2, WU-Blast2, and Ensembl human BLASTView DNA alignment programs were used for protein identification and chromosome localization. Sequence analysis was performed using TMpred and PsortII and sequence alignment was done with Multalin programs.
Transmembrane regions were predicted using TMpred software and PSORT software was used to predict protein localization in the cell. Homologs of ParAd41 were found in EMBL sequence database. Human sequences with accession numbers AF343342, AAF28985, AF201937-1 were obtained from embryonic kidney cells, C34 blood and dendritic cells, respectively; mouse sequences with accession numbers AK011085-1 and AK009237-1 were obtained from liver and tongue tissue, respectively; Arabidopsis thaliana and A. lyrata sequences correspond to accession numbers Q9SZQ8 and EFH45666; and Drosophila melanogaster sequences correspond to accession numbers CG9662 and AY070777.

2.6. Protein-Lipids Interaction. Freeze-dried lipids, PC, DPPC, PE, DPPG and PG (Sigma; P3556, P0763, P1223, P5650 and P8318, resp.,) were reconstituted with a $1: 1 \quad(\mathrm{v} / \mathrm{v})$ mixture of chloroform/methanol at $1 \mathrm{mM}$ concentration. The stock solutions were diluted in a mixture of chloroform/methanol/water $(1: 2: 0.8, \mathrm{v} / \mathrm{v})$ to obtain concentration of $1 \mathrm{mmol} / \mathrm{mL}$. Three identical aliquots of $1 \mu \mathrm{L}$ each were spotted onto the Hybond-C Extra nitrocellulose membrane (Amersham) and allowed to dry at room temperature for $1 \mathrm{~h}$. His-ParAd41 or a positive control protein GST-LL5a (Echelon Biosciences Inc), were applied to the membrane. Membranes were blocked for $1 \mathrm{~h}$ at RT in $10 \mathrm{mM}$ Tris/HCl buffer, $\mathrm{pH} 7.5$, containing $150 \mathrm{mM}$ $\mathrm{NaCl}, 0.1 \%$ Tween-20 and 3\% fatty acid-free BSA (Sigma). The membrane was then incubated overnight at $4^{\circ} \mathrm{C}$ in the same buffer containing $0.25-0.5 \mathrm{mg} / \mathrm{mL}$ of his-ParAd41 or GST-LL5a. The membranes were washed 5 times for $10 \mathrm{~min}$ in the same buffer and then incubated for $1 \mathrm{~h}$ with the anti-tag antibody (mouse, anti-His antibody, Qiagen, or rabbitanti-GST antibody, Calbiochem) in the same buffer. After three $10 \mathrm{~min}$ washes followed by overnight wash at $4^{\circ} \mathrm{C}$ without rocking and four $15 \mathrm{~min}$ washes at room temperature, the membranes were incubated for $1 \mathrm{~h}$ with anti-rabbit or anti-mouse-horseradish peroxidase conjugate (Jackson ImmunoResearch). Finally, after six 30 min washes, the interactions were detected by ECL.

2.7. Cell Culture, Transfection, Fluorescence, and Confocal Microscopy. For immunofluorescence microscopy, HeLa cells were left to adhere for 24-36 h on poly-D-lysine-coated coverslips placed in $60 \mathrm{~cm}^{2}$ Petri dishes and fixed in $2 \%$ paraformaldehyde in PBS for $20 \mathrm{~min}$ at $37^{\circ} \mathrm{C}$. After three PBS washes, cells were permeabilized with $0.2 \%$ Triton in PBS for $5 \mathrm{~min}$ at room temperature and immediately washed with PBS three times for 5-10 min each time. Cells were next incubated for $1 \mathrm{~h}$ at $37^{\circ} \mathrm{C}$ with $50 \mu \mathrm{L}$ of anti-ParAd 41 antibody diluted 1:500 in the antibody buffer (PBS containing 3\% BSA, $0.05 \%$ Tween, and $0.02 \%$ sodium azide) and then for $40 \mathrm{~min}$ with goat anti-rabbit Cy3-conjugated antibody (Millipore) diluted 1:500. The coverslips were washed with PBS (three times for $5 \mathrm{~min}$ ) and mounted on microscope slides with cryoprotector Mowiol ( $90 \%$ glycerol). Images were captured with a BX61 motorized research microscope (Olympus) and analyzed using Volocity software (Improvision). 
For transfection, $10^{5} \mathrm{HeLa}$ or Caco-2 cells in $1 \mathrm{~mL}$ EMEM supplemented with $10 \%$ FBS were seeded on glass coverslips coated with poly-D-lysine (Sigma-Aldrich) in 24well culture plates, one day before transfection. GeneJammermediated transfection procedures were performed according to the manufacturer's recommendations (Stratagene). Transfectant/DNA complexes containing $5 \mu \mathrm{L}$ GeneJammer and $1 \mu \mathrm{g}$ plasmid DNA in $100 \mu \mathrm{L}$ of serum-free EMEM were applied to coverslip overlaid with $150 \mu \mathrm{L}$ of serum-containing EMEM and incubated for $4 \mathrm{~h}$ at $37^{\circ} \mathrm{C}$, followed by addition of $0.25 \mathrm{~mL}$ of serum-containing medium. After further $44 \mathrm{~h}$, cells were washed 3 times with PBS, fixed for $10 \mathrm{~min}$ in cold absolute methanol, rinsed twice with PBS, and blocked with 5\% albumin in PBS. Cells were next incubated for $1 \mathrm{~h}$ with purified polyclonal anti-ParAd41 antibody $(1: 100)$ and goat polyclonal anti-lamin B antibody (1:150; Santa Cruz Biotechnology), both diluted in PBS. After several washes with PBS, cells were incubated with anti-rabbit Texas Red-conjugated antibody (1:100, Jackson) and anti-goat FITC-conjugated antibody ( $1: 500$, Jackson) for $1 \mathrm{~h}$ at room temperature, washed three times with PBS, and mounted in $50 \%$ aqueous glycerol. Images were collected with an MRC600 laser scanning confocal apparatus (Bio-Rad, Hercules, CA, USA) coupled to a Nikon Optiphot microscope.

2.8. Inhibition of Ad41 Infectivity. Partially purified ParAd41/AD fusion protein ( $50 \mu \mathrm{L} /$ well $)$ was added to twofold serial dilutions of Ad41 in EMEM/0.2\% FBS and incubated for $1 \mathrm{hr}$ at $37^{\circ} \mathrm{C}$. The negative controls were BSA and the activating domain alone (AD). Virion production was analyzed by immunofluorescence $24 \mathrm{~h}$ following infection [10]. BSA was added at 50-fold and ParAd41 at 500-fold molar excess with respect to fiber trimers in the sample with the highest virus concentration.

2.9. Inhibition of Virus Attachment. Confluent HeLa or Caco2 cells in 96-well plates were kept on ice for $15 \mathrm{~min}$ and washed twice with ice-cold PBS. Purified ligands diluted in cold serum-free EMEM $(50 \mu \mathrm{L})$ were added at 50 -fold molar excess with respect to the potential amount of receptor $\left(10^{5} /\right.$ cell) for $2 \mathrm{~h}$ at $4^{\circ} \mathrm{C}$, and next the cells were rinsed twice with cold PBS. The Ad 41 was added at twofold serial dilutions and allowed to attach to cells for $2 \mathrm{~h}$ at $4^{\circ} \mathrm{C}$. The virus was then removed, serum-free EMEM was added, cells were returned to $37^{\circ} \mathrm{C}$, and $24 \mathrm{~h}$ later $\mathrm{FBS}$ was added to a final concentration of $10 \%$. At $48 \mathrm{~h}$ (Ad41 on HeLa) or $92 \mathrm{~h}$ (Ad41 on Caco-2) after infection, virus multiplication was analyzed by fluorescence.

2.10. Luciferase Assay for Virus Entry. HeLa and Caco-2 cells, grown in DMEM containing 10\% FBS and 1\% essential amino acids, were seeded at $1 \times 10^{5}$ and $7 \times 10^{5}$ cells, respectively, in 24-well plates. Undifferentiated cells were used the next day after seeding. The differentiated Caco- 2 cells were obtained after 12-day culture with the medium changed every three days. The cells were washed twice with cold PBS, and the recombinant viruses Ad5.SF40Luc, Ad5.LF40Luc, and Ad2Luc at $2.77 \times 10^{10}, 5 \times 10^{10}$, and $5 \times 10^{8}$
TCID $50 / \mathrm{mL}$, respectively, which had been diluted in PBS by twofold serial dilutions to obtain a MOI of 500, 250, 125, 62, and 31 , were applied for $2 \mathrm{~h}$ at $4^{\circ} \mathrm{C}$. After supernatant removal, cells were washed twice with cold serum-free DMEM and overlaid with DMEM containing $0.2 \%$ FBS. Next day, the medium was changed to DMEM containing $10 \%$ FBS. The luciferase assay was performed one day after infection for HeLa cells and 3 days after infection for both differentiated and undifferentiated Caco- 2 cells. For this, the medium was removed and cells were rinsed with $1 \mathrm{~mL}$ of PBS, and then $200 \mu \mathrm{L}$ of Cell Culture Lysis Reagent (Promega) was added to each well for $10 \mathrm{~min}$. The content of each well was clarified for $5 \mathrm{~min}$ at $5000 \mathrm{rpm}$. Luciferase assay was performed in $20 \mu \mathrm{L}$ of the lysis supernatant using Lumat LB9501 (Berthold) luminometer.

\section{Results}

3.1. ParAd41, a Partner of the Ad41 Short Fiber. To identify partner proteins of the Ad41 short fiber, we chose the yeast two-hybrid system that provides an assay for the study of protein-protein interaction occurring within eukaryotic cells. We have chosen the library from the Ad41-permissive human embryonic kidney cell line 293 [11], with the Ad41 short fiber head domain (HSF41) as a bait. Native fiber protein being trimeric, it was imperative to know if the head domain in fusion with GAL4BD is a trimer. For this, cross-linking analysis followed by Western blotting was employed. The molecular mass of head domains together with the BD is about $40 \mathrm{kDa}$. Accordingly, the monomers in fusion with $\mathrm{BD}$ were observed at $40 \mathrm{kDa}$ and the trimeric forms of fusion proteins run at $120-130 \mathrm{kDa}$ (Figure 1(a)).

Among several Ad41 short fiber partners revealed by the two-hybrid system [12], we identified a novel human protein that we named Partner of enteric Ad41short fiber (ParAd41). In the mating assay, the ParAd41 interacted only with the HSF41 and did not bind the either long fiber head domain (HLF41) or the head domain of Ad2 fiber (H2 in Figure 1(b)), demonstrating the specificity of this interaction for the Ad41 short fiber.

3.2. ParAd41 Sequence Analysis. ParAd41 is a 149 amino acid protein with three putative transmembrane domains (Figures 2(a) and 2(b)). Additionally, it contains a putative myristoylation site within the second transmembrane domain and a site that mediates recognition by ERK MAP kinase [13]. We also noticed the presence of two GxxxG/S motifs known to be involved in oligomerization of straight $\alpha$-helices found in naturally occurring helical membrane proteins [14].

ParAd41 gene seems to occur several times in the human genome (chromosomes 1, 4, 6, 9, and 19), including twice in chromosomes 1 and 6 . No splicing was observed for matching genes localized in chromosomes 1, 4, and 6. A database search revealed several similar DNA sequences from various organisms, encoding, with one exception, proteins of unknown function (Figure 2(c), Table 1). The most similar to ParAd41 are sequences deduced from human and mice cDNA whereas $A$. thaliana and D. melanogaster sequences 


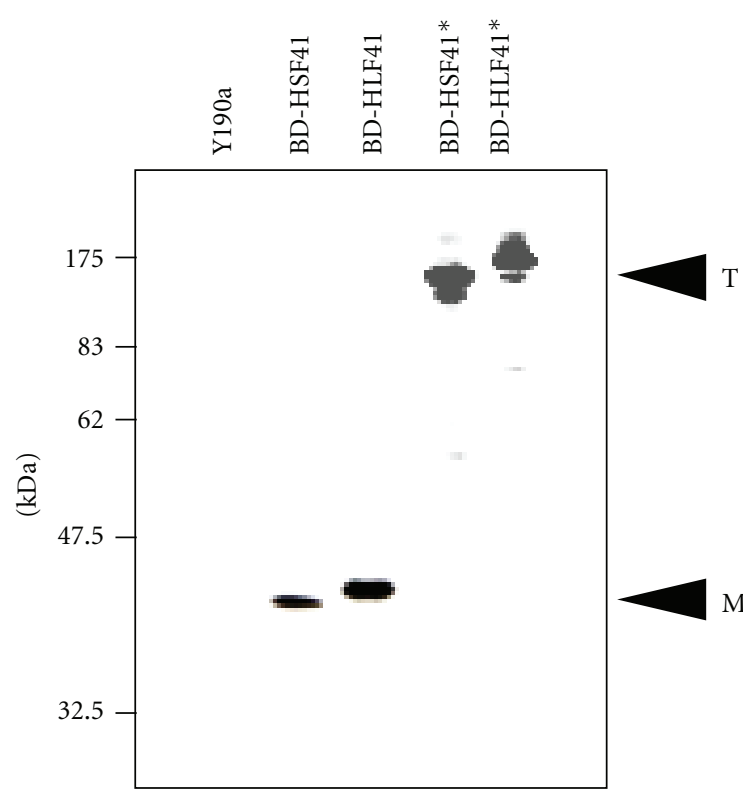

(a)

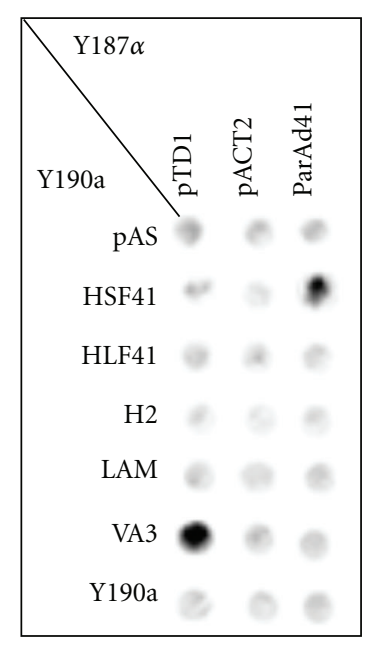

(b)

FIGURE 1: Two-hybrid system. (a) Oligomeric character of the baits used in the two-hybrid system. Yeast extracts expressing head domains of the Ad41 short and long fibers in fusion with binding domains (BD-HSF41 and BD-HLF41) were analyzed on PAGE under denatured and semidenatured (no boiling) conditions. The baits were revealed with anti Ad2-fiber protein. T-trimer, M-monomer. (b) Yeast mating test. The plasmids of the positive clones were isolated and used for transformation of the Y187a yeast strain. The baits: binding domain of GAL4 fused with the head domain of Ad41 short (HSF41) or long (HLF41) fibers or with the head domain of respiratory Ad2 strain fiber (H2) and the controls (negative-pAS and LAM, a positive-VA3), all in the Y190a strain, were mated with the positive clones in Y187a.

are less well conserved. Of interest is the similarity, albeit less pronounced, with DC2 protein from Chlamydomonas [15]. This protein is a part of the outer dynein armdocking complex, a microtubule-associated structure, which targets the dynein outer arm to its binding site on the flagellar axoneme [16]. A homologous protein of $66 \mathrm{kDa}$ was recently found in sperm flagella of ascidian Ciona intestinalis [17]. All these sequences contain the GxxxG or similar SxxxS, (VLI) $x x x(V L I)$ and (VLI)Gxx(VLI) motifs, which are involved in transmembrane helix-helix association resulting in protein oligomerization [14]. The basic character of ParAd41 (predicted isoelectric point of 9.41) is conserved among all analogs showing theoretical pI between 9.41 and 10.14 (Table 1). Protein localization prediction (PSORT II) suggested the presence of ParAd41 in the endoplasmic reticulum.

3.3. Recombinant ParAd41 Expression and Purification. Histagged ParAd41 was insoluble upon expression in bacteria but could be solubilized in the presence of detergents (Figure $3(\mathrm{a})$ ), which enabled its partial purification in the native state. The theoretical MW of ParAd41 is about $16 \mathrm{kDa}$, and mass spectroscopy analysis of the recombinant protein yielded the value of 16646 (results not shown); however, we observed a PAGE-SDS mobility at somewhat above the $25 \mathrm{kDa}$ marker. Of note, it was already observed that hydrophobic proteins tend to have much lower mobility than predicted [12]. The recombinant ParAd41 was insoluble upon expression in $E$. coli but could be isolated and purified under denaturing
TABLE 1: Predicted isoelectric point (pI) of ParAd41 homologs.

\begin{tabular}{lccc}
\hline Protein & pI & Species & aa \\
\hline AF343342 (ParAd41) & 9.41 & Human, HEK cells & 149 \\
AAF28985 & 9.79 & Human, C34 blood cells & 167 \\
AF201937 & 9.41 & Human, dendritic cells & 149 \\
AAF86873 (DC2) & 9.41 & Human, dendritic cells & 149 \\
AK011085 & 9.41 & Mouse, liver & 149 \\
AK009237 & 9.41 & Mouse, tongue & 149 \\
Q9SZQ8 & 9.85 & A. thaliana & 172 \\
EFH45666 & 9.85 & A. lyrata & 173 \\
CG9662 & 9.47 & D. melanogaster & 129 \\
AY070777 & 10.11 & D. melanogaster & 75 \\
Q6Z6Q1 (DC2) & 10.14 & Chlamydomonas & 177 \\
\hline
\end{tabular}

conditions. The polyclonal antibody purified with the aid of renatured protein demonstrated some propensity of ParAd41 for oligomerization (Figure 3(b)). This concurs with the presence of GxxxG, or the similar SxxxS motif, involved in transmembrane helix-helix association, possibly resulting in protein oligomerization [14]. The ParAd41 protein is able to interact with phospholipids (Figure 3(c)), which substantiates its membrane character.

3.4. Intracellular Localization of ParAd41. ParAd41 protein in nontransfected HeLa and transfected HeLa and Caco-2 cells was observed by fluorescence and confocal microscopy 


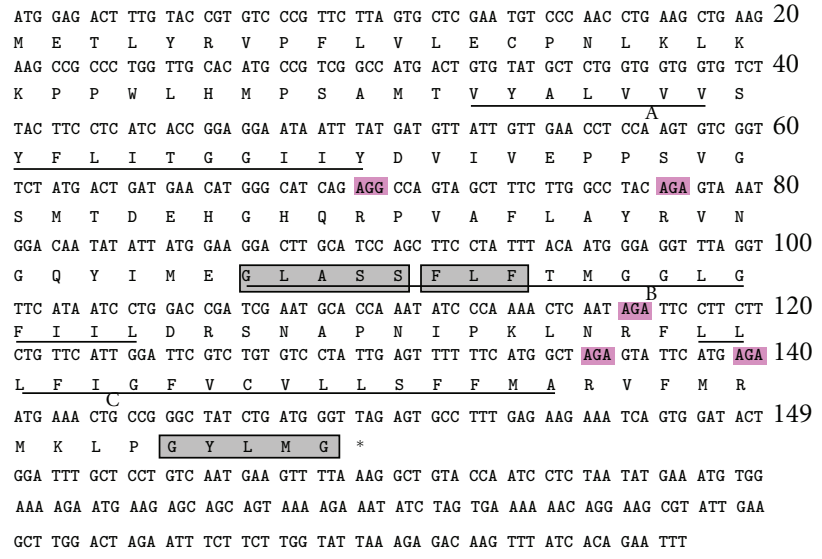

(a)

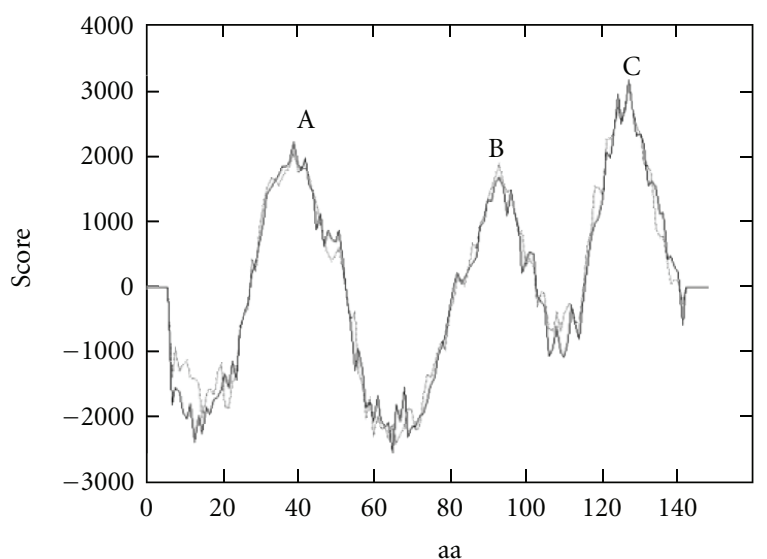

(b)

\begin{tabular}{|c|c|}
\hline ParAd41 & -----------------METLYRV----PFLVLECPNLKLKKPPWLHMPS AMTVY|ALVVVSYF \\
\hline AF201937 & 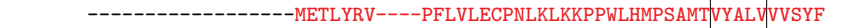 \\
\hline AK009237_1 & ------------------METLYRV----PFLVLECPNLKLKKPPWVHMPSAMTVYALVVVVSYF \\
\hline AK011085_1 & -----------------METLYRV----PFLVLECPNLKLKKPPWVHMPSAMTVYALVVVVSYF \\
\hline AAF28985 & FPGGAWGLRPRTALAATNMETLYRV----PFLVLECPNLKLKKPPWLHMPSAMTVYYLVVVVSYF \\
\hline CG9662 & ----------------MIETL YNL----PFHILVPPNIKVRRFS-IPMPSPMAVVFSVILFSYF \\
\hline Q9SZQ8 & MAPRSDSQTLATGSD-ENESSIDPIFHILRII----PFSFLRPPRLRLKLPSFT-LPSPMTVFSLILLTYF \\
\hline 064567 & MAPRSDSQTGSSVSDGSDQSSMDPIFHLLRIV----PFSFLRPPRLRLKIPSFT-LPSPMTVYALILLTYF \\
\hline AY070777 & 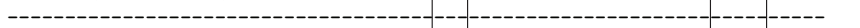 \\
\hline DC2 & MAPRSDSATGGAAAAQAHGSDFDSI-DPLFHVLRVLFSFLRPPRTRLRLPSNLALPSPMTVFALILLTYF \\
\hline ParAd41 & LITGGIIYDVIVEPPSVGSMTDE-HGHQRPVAFLAYRVNGQYIMEGLASSFLFTMGGLGFIILDRSN \\
\hline AF201937 & LITGGIIYDVIVEPPSVGSMTDE-HGHQRPVAFLAYRVNGQYIMEGLASSFLFFTMGGLGFIILDRSN \\
\hline AK009237_1 & LITGGI IYDVIVEPPSVGSMTDE-HGHQRPVAFLAYRVNGQYIMEGLASSFLFTMGGLGFIILDRSN \\
\hline AK011085_1 & LITGGIIYDVIVEPPSVGSMTDE-HGHQRPVAFLAYRVNGQYIMEGLASSFLFTMGGLGFIILDRSN \\
\hline AAF28985 & LITGGI IYDVIVEPPSVGSMTDE-HGHQRPVAFLAYRVNGQYIMEGLASSFLFTMGGLGFIILDRSN \\
\hline CG9662 & LVTGGIIYDVIVEPPSLGAT--------------------YIMEGLASSFLFTVGGLGFIIMDQTH \\
\hline Q9SZQ8 & LVVSGFVYDVIVEPPGIGSTQDPITGSVRPVVFMSGRVNGQYI IEGLSSGFMFVLGGIGIIMLDLAL \\
\hline 064567 & LVVSGFVYDVIVEPPGIGSTQDPTTGTIRPVVFMSGRVNGQYIIEGLSSGFMFVLGGIGIVMLDLAL \\
\hline AY070777 & 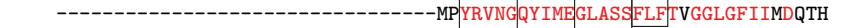 \\
\hline DC2 & AVVSGLVYDVIVEPPGIGSVQDPATGAVRPVVFLPGRVNGQYIIEGLSSGIMFVIGGIGIILLDLAV \\
\hline ParAd41 & APNIPKLNRFLLLFIGFVCVLLSFFMARVFMRMKLPGYLMG \\
\hline AF201937 & APNIPKLNRFLLLFIGFVCVLLSFFMARVFMRMKLP|GYLMG \\
\hline AK009237_1 & APNIPKLNRFLLLFIGFVCVLLSFFMARVFMRMKLPGGLMG \\
\hline AK011085_1 & APNIPKLNRFLLLFIGFVCVLLSFFMARVFMRMKLP GYLMG \\
\hline AAF28985 & APNIPKLNRFLLLFIGFVCVLLSFFMARVFMRMK------- \\
\hline CG9662 & TPGKTNLNRLLLTAMGF IFILVSFFTTWLFMRMKLPSYLQP \\
\hline Q9SZQ8 & DKNRAKSVKASYATAGVSSIVIAYVMSMLFIRIKIPGYLR- \\
\hline 064567 & DKNKAKSVKASYAVAGVSSIVIAYVMSMLFIRIKIPGYLY- \\
\hline AY070777 & TPGKTNLNRLLLTAMGFIFILVSFFTTWLFMRMKLPSYLQP \\
\hline DC2 & DRNRPRSLRVSFGGSGVAAIVIAYAMAMLFLRIKIPGYLW- \\
\hline
\end{tabular}

(c)

FIgURE 2: General characterization of ParAd41. (a) DNA and protein sequences. The putative transmembrane domains are underlined. The GxxG/S motifs mediating high-affinity helix-helix association in membrane proteins and the FxF motif that mediates recognition by ERK MAP kinase are boxed. Rare codons are in pink. (b) Hydrophobic score of transmembrane domains A, B, and C found in ParAd41. (c) Alignment of primary sequences of unknown proteins, ParAd41 homologs, with Multalin using indicated Genbank accession numbers (AF343342 for ParAd41). Conserved GxxxG motifs are boxed. The color code is the same as that used by the ClustalX server.

using the affinity-purified antibody obtained against bacterially expressed recombinant ParAd41. The ParAd41 (in red), both the endogenous one and the transiently expressed, could be clearly seen in the cytoplasm as well as around the nucleus (Figure 4). The intracytoplasmic images are reminiscent of localization in intracellular membranes, most likely in the endoplasmic reticulum (ER) and the Golgi apparatus, which is substantiated by colocalization with COP (Figure 4(c)), proteins involved in endocytosis at the ER and the Golgi apparatus, (for review, see [18]). In addition, ParAd41 overlapped with tubulin, a major component of microtubules, and was able to associate with the mitotic spindle (shown in the lower row of the upperFigure 4(c) panel). Importantly, a part of the ParAd41 overlapped with lamin B (Figure 4(b)), an integral membrane protein of inner membrane of nuclear envelopes (for review see [19]). These combined observations rather exclude an external membrane localization of ParAd41 and suggest that it may interact with the Ad41 short fiber in steps subsequent to the initial virus attachment, such as virus endocytosis and attachment to the nuclear envelope. It is relevant that adenovirus replication occurs in the nucleus [20]. 


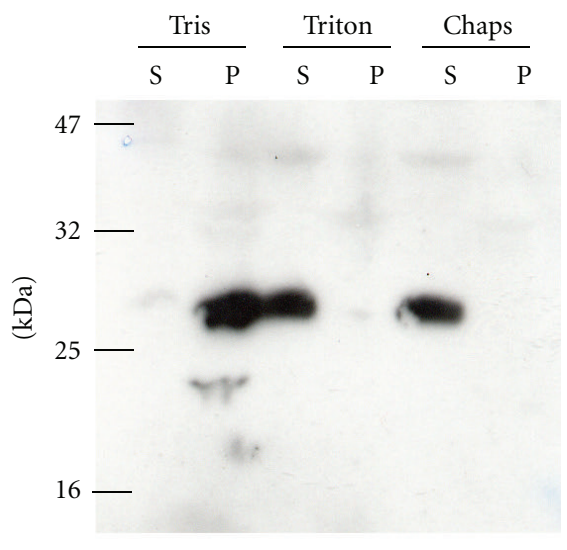

(a)
Anti-His/GST

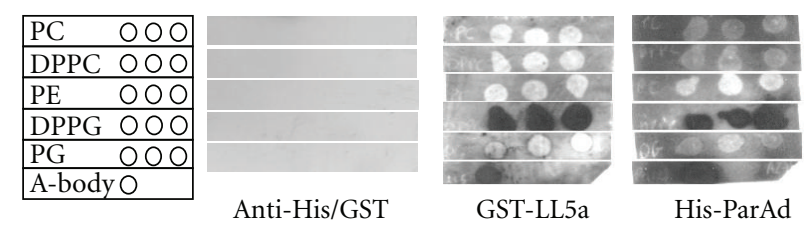

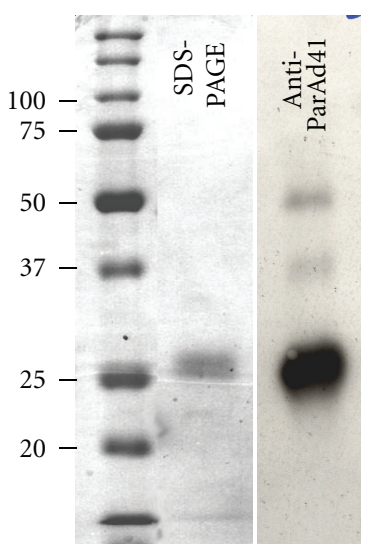

(b)

(c)

Figure 3: Properties of the recombinant His-tagged ParAd41. The His-tagged ParAd41 was expressed in bacteria. After cell lysis in the absence of detergent, the recombinant protein was recovered in the pellet. (a) Solubility of the recombinant protein expressed in bacteria. S-soluble fraction, $\mathrm{P}$ - pellet. (b) Oligomeric state. His-ParAd41 purified under denaturing conditions was analyzed by SDS-PAGE. Left panel-staining with CBB, right panel-Western blot with anti-ParAd41 antibody. (c) His-ParAd41 interaction with lipids (see Section 2). LL5a-positive control protein.

3.5. Effect of ParAd41 on Ad41 Infection. The effect of ParAd41 on virus infection could be analyzed thanks to the availability of ParAd41 fused to the activation domain of GAL4 (ParAd41/AD), which rendered the protein soluble. Increasing amounts of Ad41 were allowed to interact with $\mathrm{AD}$ alone, with BSA, or with ParAd41/AD, and then the cells were cultured at $37^{\circ} \mathrm{C}$ to allow infection with Ad41. Virus interaction with the AD alone did not significantly affect the yield of virus progeny, and the interaction of viral inoculum with BSA had some positive, albeit small, effect on virus progeny (Figures 5(a) and 5(b)). Contrary to that, pre-incubation of Ad41 with ParAd41/AD resulted in clear decrease in viral progeny production (Figure 5(c)). This rather moderate inhibition level-up to three times-is real, as it increased with increasing the dose of ParAd41. These results suggest that ParAd41 interaction with Ad41 short fiber is quite stable. Most importantly, they show that the attachment of recombinant ParAd41 to short fibers in the virus particles results in inhibition of the infection process, which demonstrates the essential role of ParAd41 in enteric Ad infection.

3.6. Involvement of Different Fiber Proteins in Ad Cell Entry and Infection. Since inhibition of infection obtained with ParAd41 fused to the AD of GAL4 (ParAd41/AD) was rather moderate, we thought to define the role of fiber proteins in enteric virus infection by analyzing the effect of adenoviral ligands first on Ad41 cell attachment and then on the postattachment step.
It has been recognized that the globular distal C-terminal head domain of Ad trimeric fibers is a receptor-binding domain. For the enteric serotypes 40 and 41 that possess two kinds of fibers of different length, it has been shown that the head domain of the long fiber, but not that of the short one, was able to inhibit Ad41 attachment to A549 cells [4]. In the attachment inhibition experiments, we used native fiber of Ad5 purified from Ad5-infected cells (F5) and native Ad41 pentons (from Ad41-infected cells) containing penton bases with either long or short fibers (LP41 and SP41). The viral ligands were added to HeLa and Caco- 2 cells in 50-fold excess over the number of fiber receptors $[21,22]$ and were allowed to saturate cells at $4^{\circ} \mathrm{C}$. Ad41 infection was synchronized by attachment in the cold, and then after removal of excess ligand, the virus was allowed to multiply, which was followed by the estimation of the level of virus proteins (Figure 6).

First we confirmed that the fiber protein in used ligands-F5, LP41, and SP41-was trimeric (furthest right panel in Figure 6). As expected, attachment of the Ad5 fiber to cells resulted in significant inhibition of the Ad41 entry (Figure 6(b), Ad41/F5); it is known that the Ad41 long fiber employs CAR as a receptor, similarly to the Ad5 fiber [4]. When the pentons of Ad41 were used in similar experiments with HeLa cells, the presence of long fiber in pentons was sufficient to cause inhibition of Ad41 attachment (Figure 6(a), right panel). Similarly as observed with Ad5 fiber, a large proportion of CAR, up to $70 \%$, could be neutralized. Contrary to this, no Ad41 inhibition was observed with Ad41 pentons containing short fiber (Figure 6(a), right panel), 
Anti-ParAd41 + Hoechst
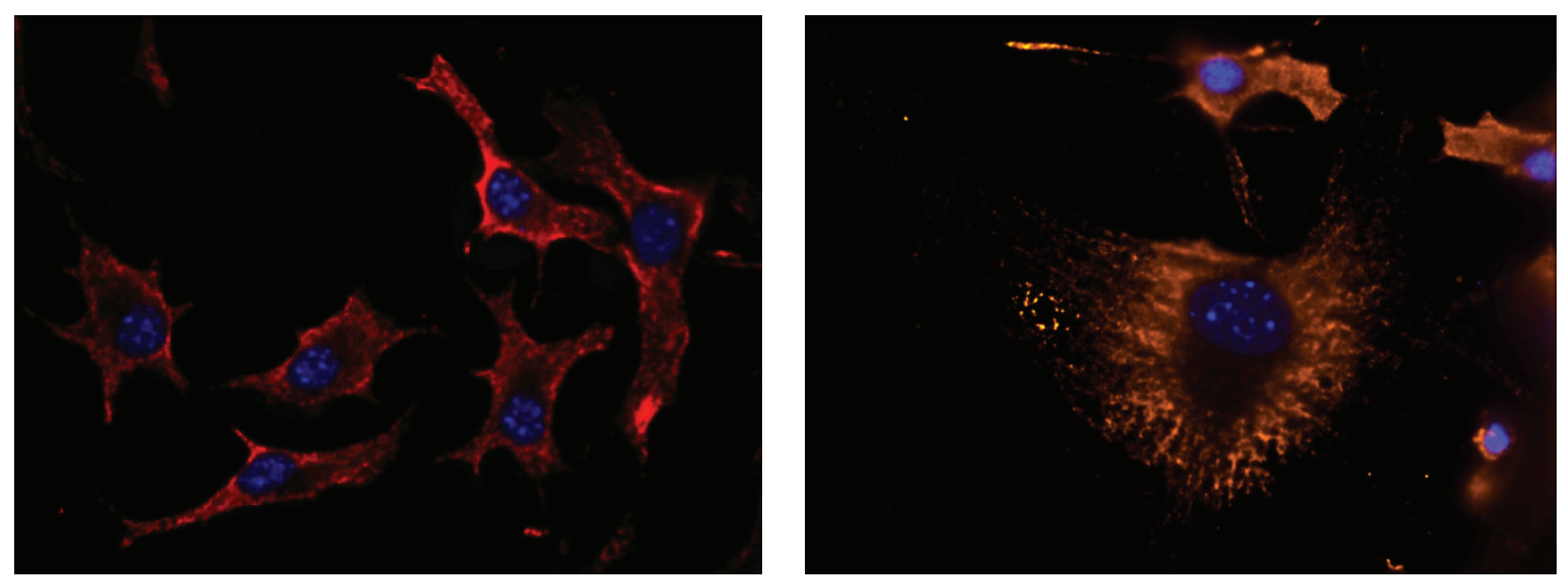

Anti-ParAd41
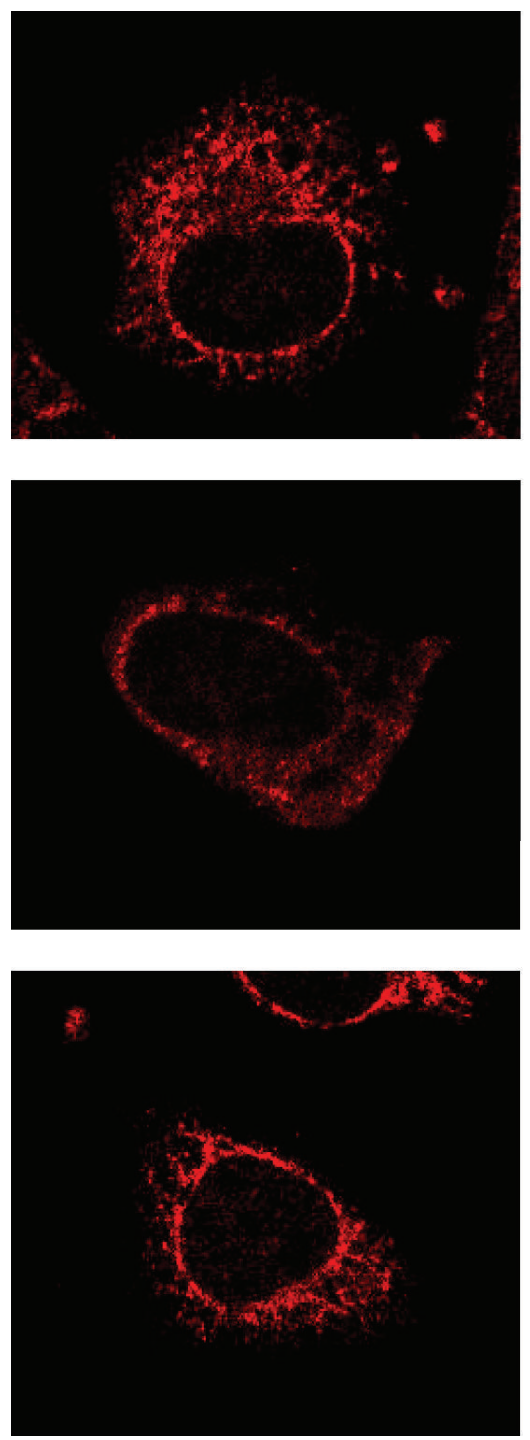

(a)

Anti-lamin B
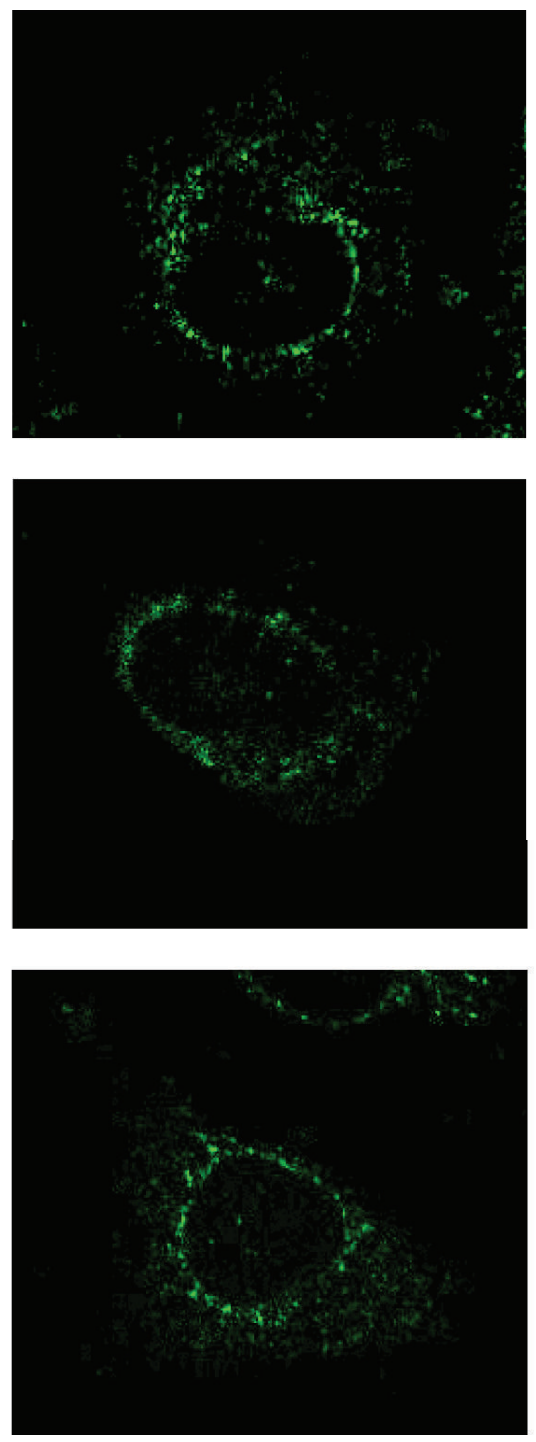

(b)
Merge
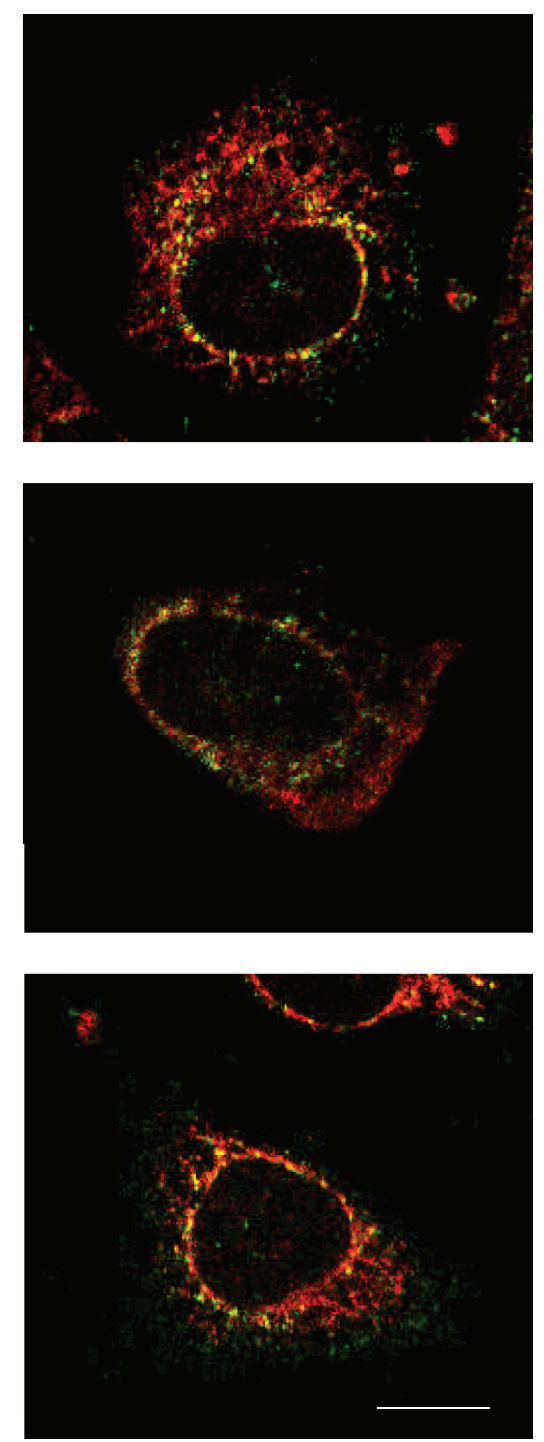

FIgURE 4: Continued. 


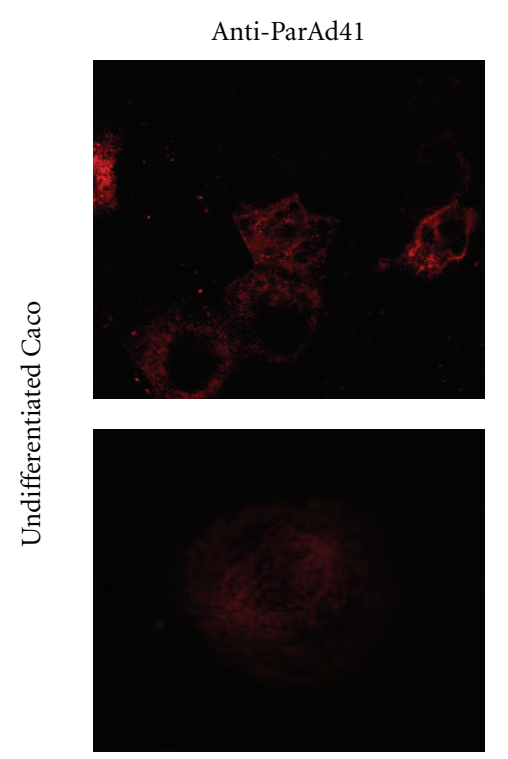

Anti-ParAd41

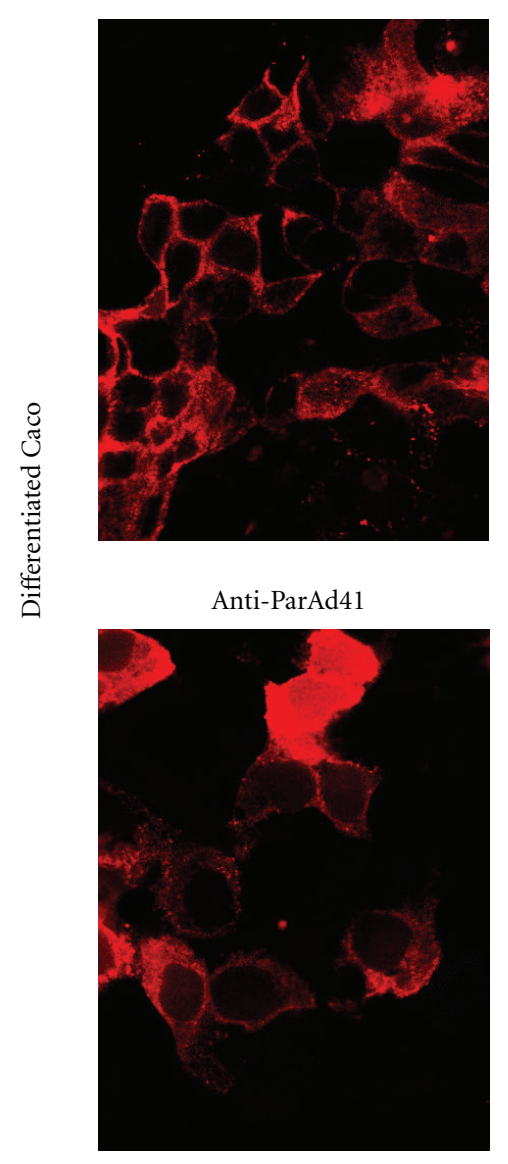

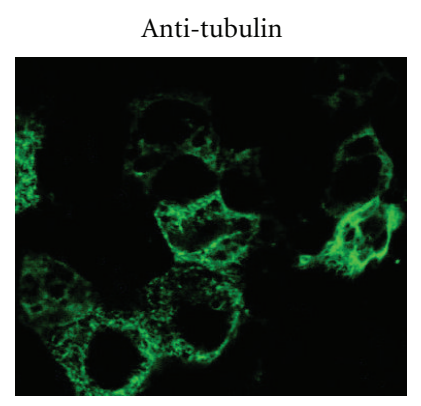
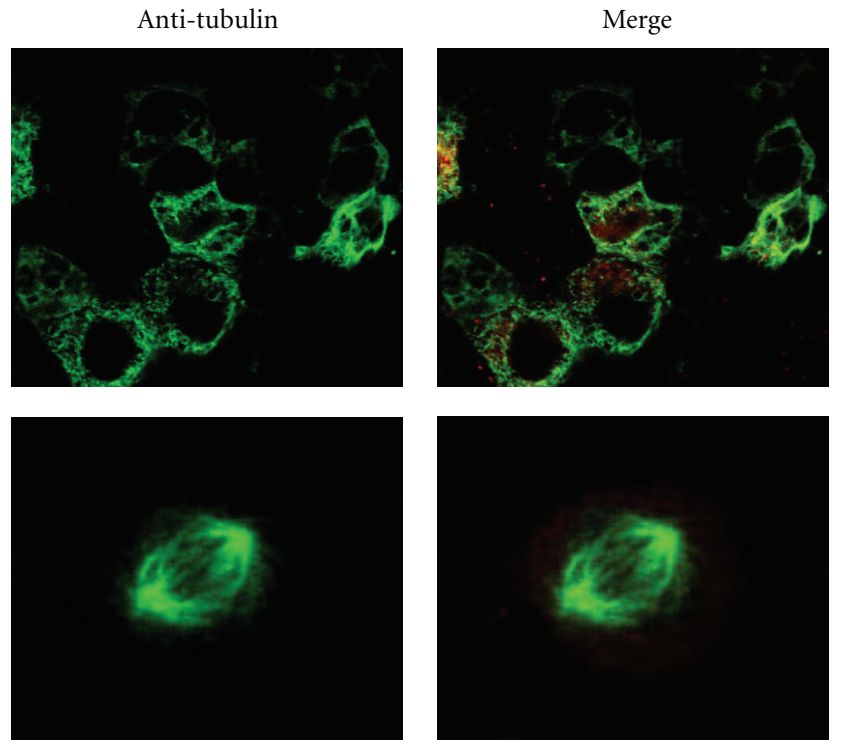

Anti-tubulin

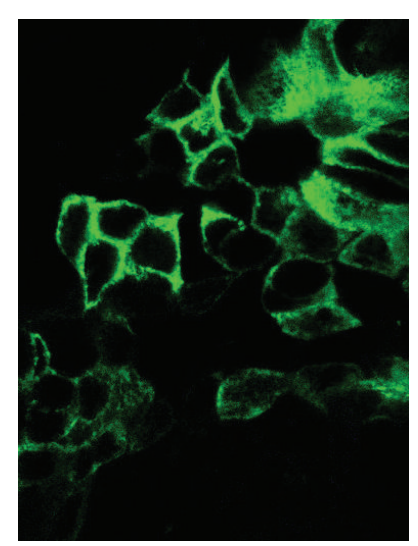

Anti-COP

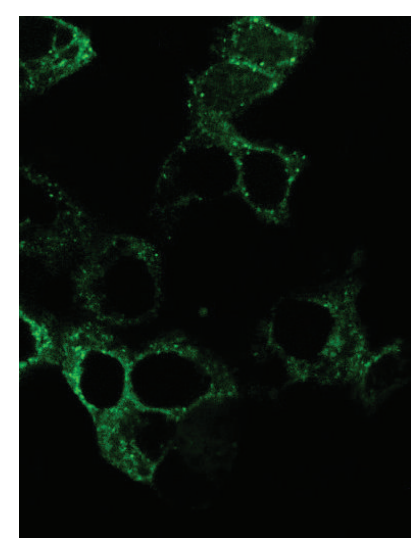

(c)

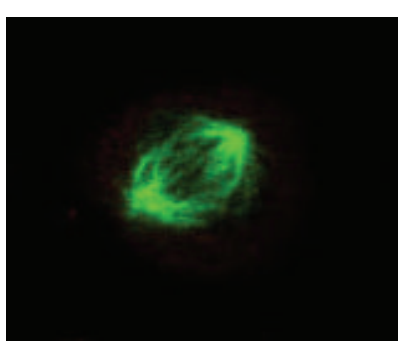

Merge

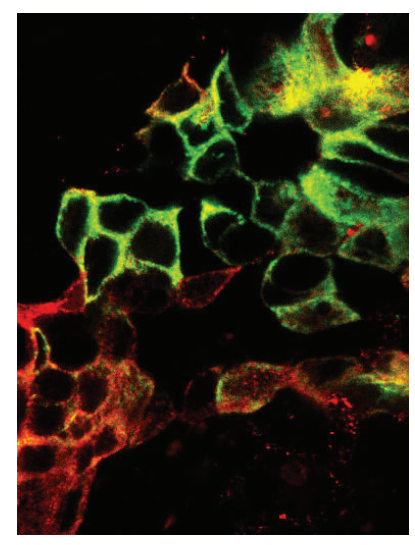

Merge

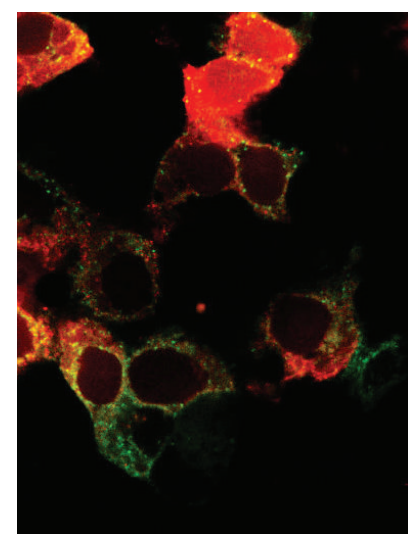

Figure 4: Intracellular localization of ParAd41. (a) Endogenous ParAd41 in HeLa cells analyzed by immunofluorescence microscopy. Fixed cells were incubated with anti-ParAd41 antibody (red signal) and counterstained with the nuclear dye Hoechst (upper panel). (b) Transfected and fixed HeLa cells were incubated simultaneously with anti-ParAd41 (red signal) and anti-lamin B (green signal) and analyzed by confocal microscopy. (c) Transfected Caco-2 cells (undifferentiated: upper panel and differentiated: lower panel) were fixed, incubated with antiParAd41 and anti-tubulin or anti-COP antibodies (green signals), and analyzed by confocal microscopy. 


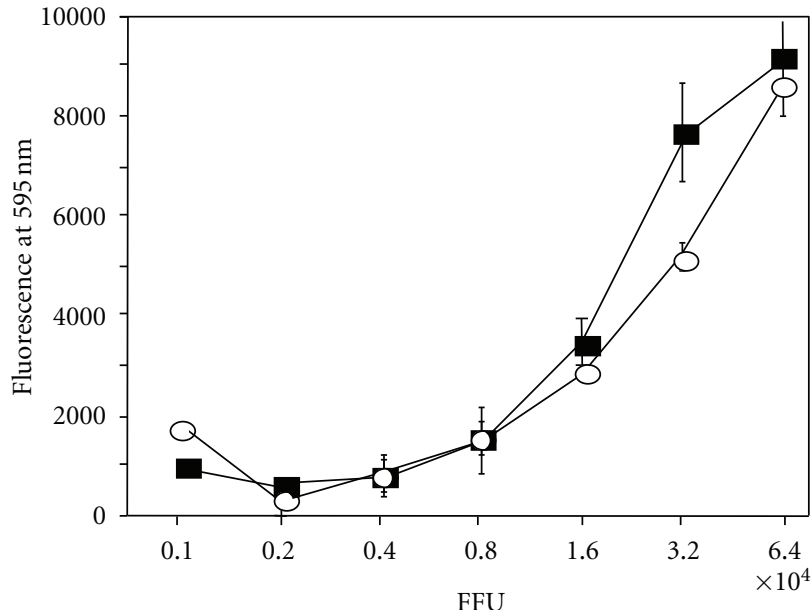

Ad41 Ad $41+A D$

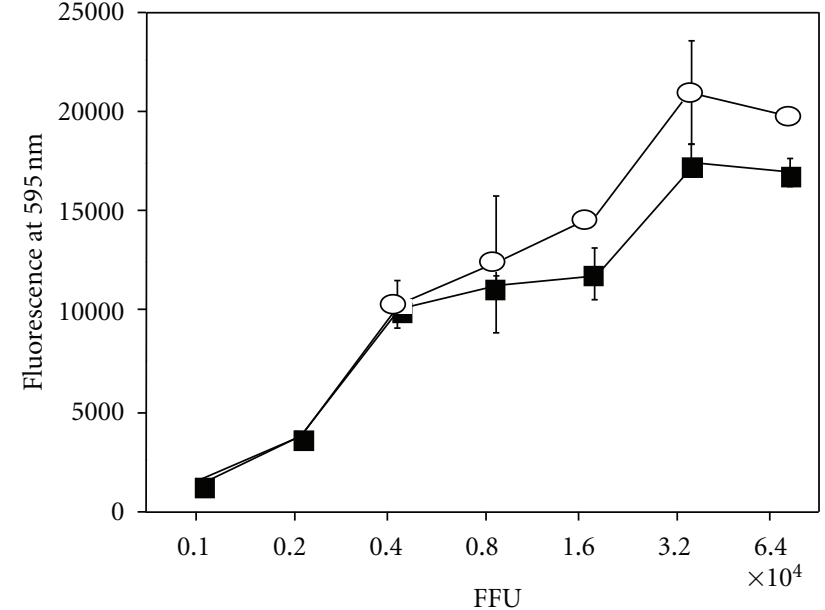

Ad41

-O- Ad41+BSA

(b)

(a)

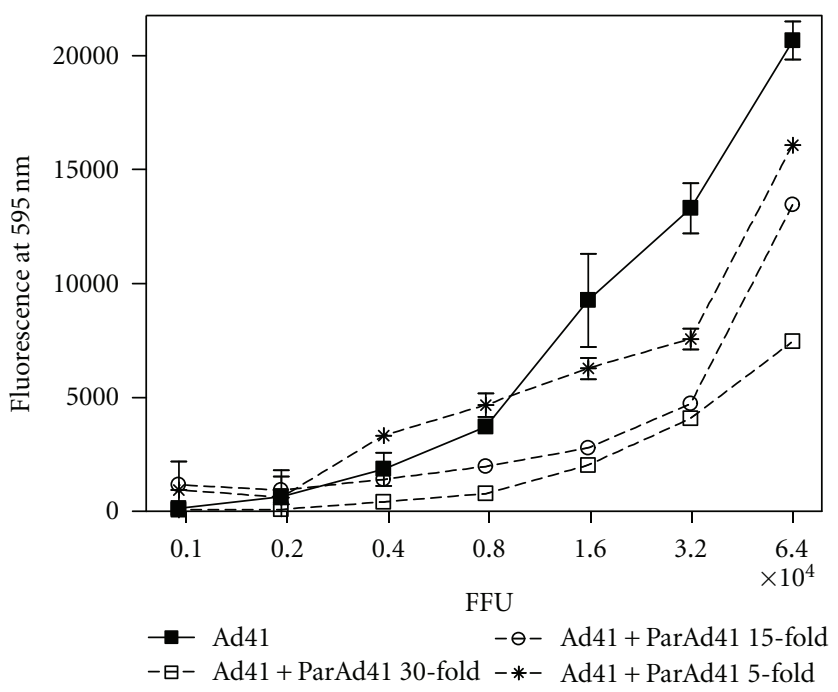

(c)

FIgURE 5: Inhibition of Ad41 infectivity. The Ad41 was incubated with the activating domain alone (a), BSA (b) or fusion protein ParAd41/AD (c) and was allowed to infect cells in culture as described in Section 2. Viral protein production was analyzed by immunofluorescence $24 \mathrm{~h}$ after infection.

confirming the lack of involvement of Ad41 short fiber in virus attachment. Both Ad41 pentons contain the same Ad41 $\mathrm{Pb}$ protein, and these results show that under the conditions used, the base protein has no effect on Ad41 attachment. Similar results were obtained for experiments performed on un-differentiated Caco-2 cells (Figure 6(b), left panel). For differentiated Caco-2 cells, the Ad41 attachment was similarly inhibited by the Ad5 fiber and the Ad41 long pentons but also, interestingly, to some extent by the Ad41 short pentons (by approximately 25\%, Figure 6(b), right panel).

Next, we studied the effect of these fibers on virus entry and infection, in comparison with the respiratory Ad2 serotype (Ad2Luc), using the recombinant Ad5 bearing either short or long fibers of enteric Ad40 (Ad5.LF40Luc and Ad5.SF40Luc). These viruses carry also the luciferase gene under the CMV promoter, which enables to see whether the virus attached to cells, penetrated, and was liberated in the cytoplasm and that its DNA was injected into the cell nucleus, permitting the formation of mRNA for luciferase expression. The results obtained at different virus multiplicity of infections (MOI) demonstrate that Ad2 infection was successful in HeLa and undifferentiated Caco2 cells but severely hampered in Caco-2 differentiated cells (Figure 6(c)). Ad5.LF40Luc entry and subsequent infection was rather moderate in HeLa and undifferentiated Caco-2 cells but very efficient in differentiated Caco- 2 cells. Finally, Ad5.SF40Luc was unable to enter on its own the HeLa and undifferentiated Caco-2 cells, while it penetrated differentiated Caco- 2 cells very efficiently. 

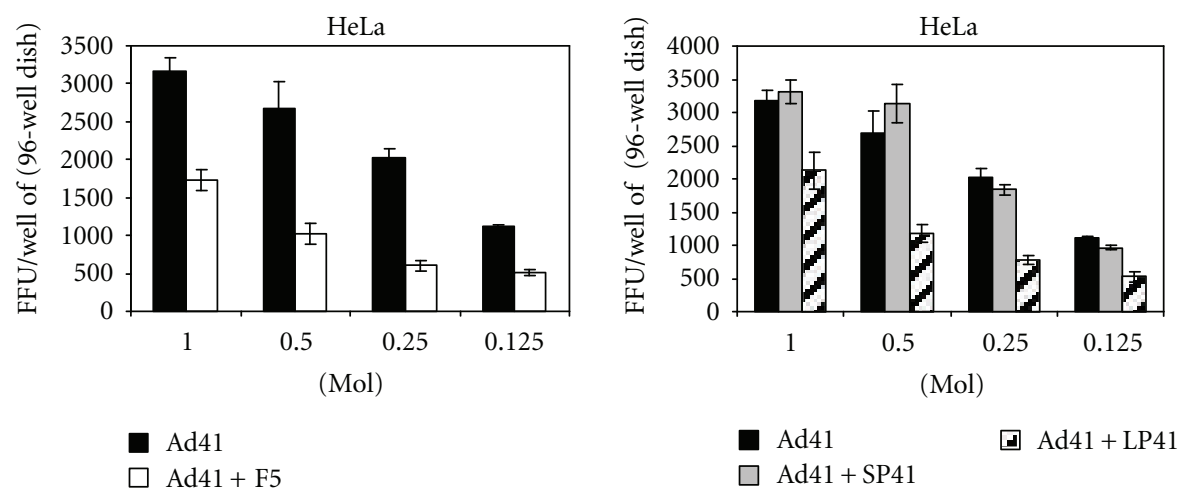

(a)
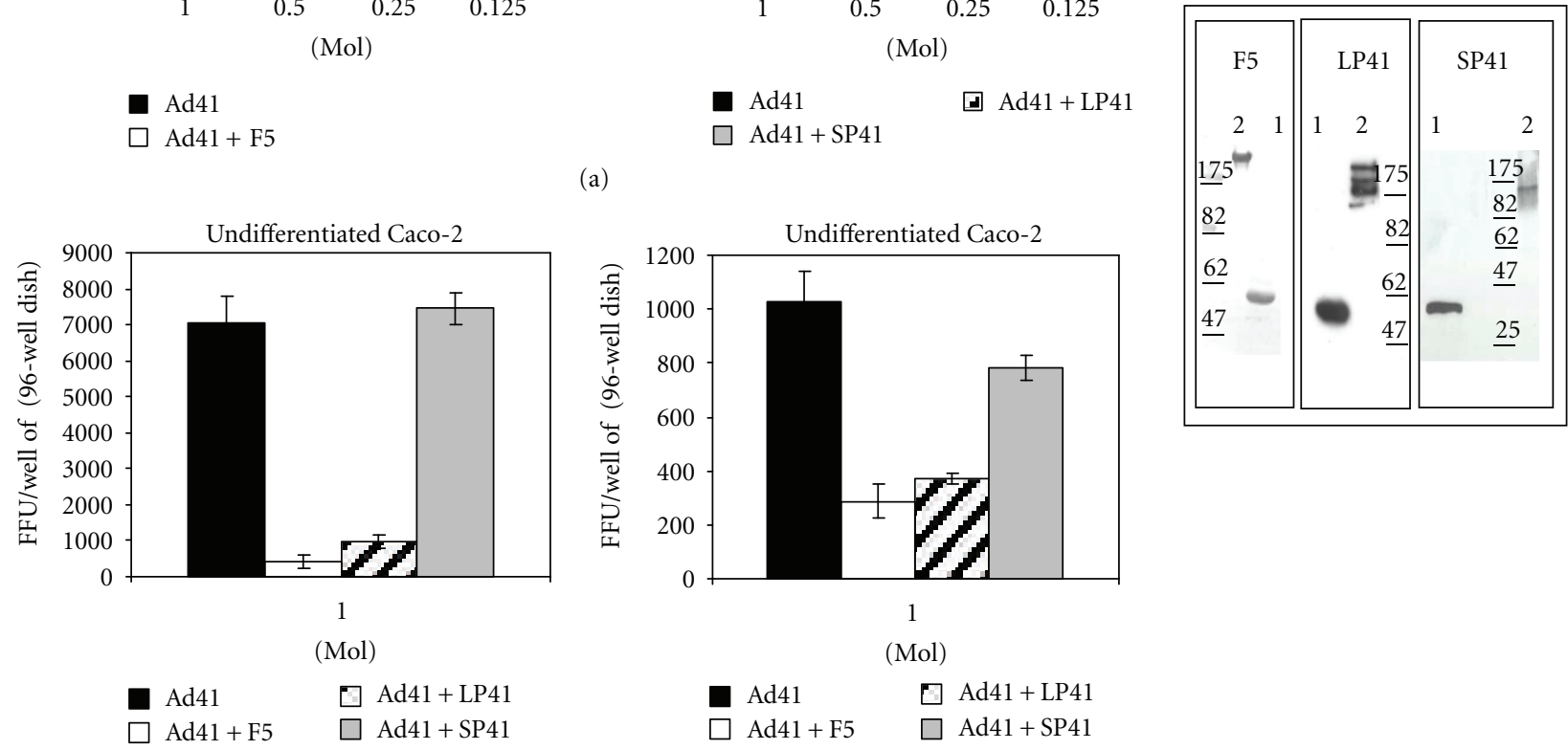

(b)
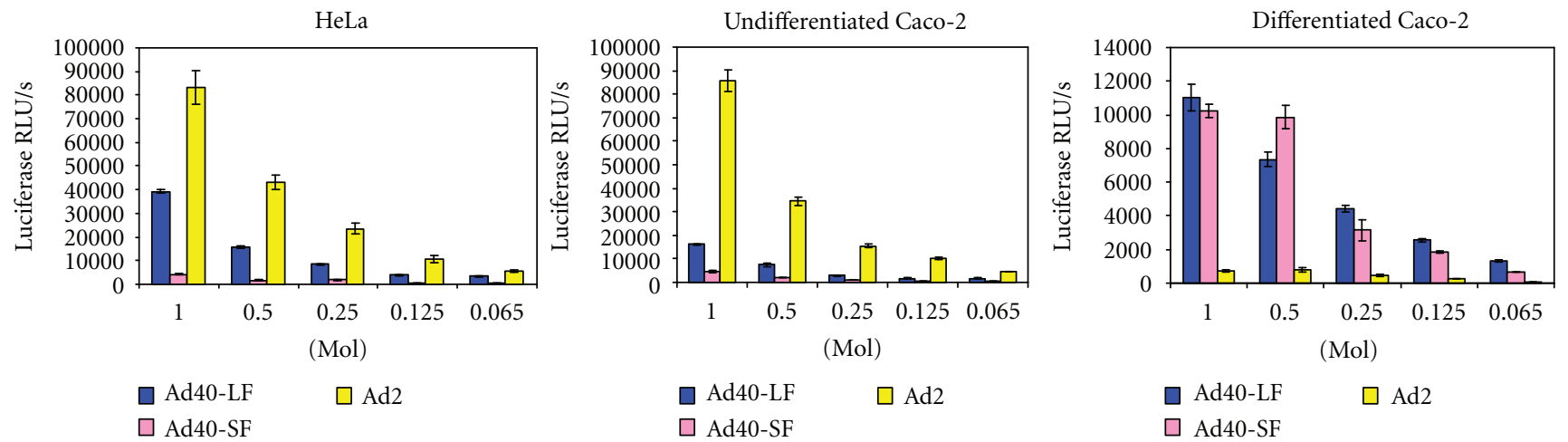

(c)

FIGURE 6: Effect of ParAd41 on Ad41 attachment and postattachment step. ((a), (b)) Inhibition of Ad41 attachment. Ligands indicated above figures were allowed to interact with cells at $4^{\circ} \mathrm{C}$. Different (a) or constant amounts (b) of Ad41 were allowed to attach to cells at $4^{\circ} \mathrm{C}$ and virus yield was assessed after one round of replication at $37^{\circ} \mathrm{C}$, as described in the Section 2. (c) Postattachment cell entry of adenoviruses bearing different fiber proteins. The entry of Ad2Luc was compared to that of chimeric Ad5.LF40.Luc (Ad5:40-LF) and Ad5.SF40.Luc (Ad5:40-SF). Virus attachment was performed at $4^{\circ} \mathrm{C}$ for $2 \mathrm{~h}$, and the luciferase expression was measured at one or three days after infection, respectively, for HeLa and Caco-2 cells.

\section{Discussion}

This study is the first one to probe the molecular nature of enteric Ad41 tropism. While the majority of human Ads have one kind of fiber, the enteric serotypes (Ad41 and Ad40) possess two fibers of different lengths and primary sequences.
Our starting point was the observation by Roelvink et al. [4] that the short Ad41 fiber does not seem to recognize specific primary receptors in the plasma membrane. This has been reinforced by the observations ofLouvard et al. [23] that Ad5SHORT, a recombinant virus bearing the Ad41 short fiber, is by itself unable to mediate Ad41 affinity 
for enterocytes, the natural target tissue of enteric Ads. In addition, the secondary receptors responsible for endocytosis of serotypes $2,3,4$, and 12 are integrins av $\beta 3$ and av $\beta 5$ [22, $24]$, and that interaction of Ad penton base $(\mathrm{Pb})$ protein $\mathrm{RGD}$ motif with these integrins has been shown to be necessary for Ad internalization. However, Ad40 and Ad41 lack av $\beta 3$ and av $\beta 5$ ligand (RGD motif) in their Pbs, and Ad41 entry is most probably independent of av integrins [25]. Finally, the physicochemical features of respiratory Ads are quite different from those of enteric Ads fibers, which permits the survival of the latter under acidic conditions imitating those existing in the gastrointestinal tract [26]. These combined data together clearly showed that the cell entry of enteric Ads is different from that of the respiratory serotypes and that the short fiber of enteric Ads is not involved in virus attachment to the external plasma membrane receptor.

Since the attachment receptor for the long fiber of enteric Ads is the same as for the respiratory Ad serotypes, we reasoned that the specific tropism of enteric serotypes could be due in part to the function of some other partner(s) interacting specifically with the short fiber, possibly subsequently to the attachment step. Identified here the novel human protein of a pronounced hydrophobic character, ParAd41, interacts with the short fiber (but not with the long one) of the enteric Ad. Importantly, saturation of short fibers through in vitro interaction with the recombinant ParAd41 protein results in inhibition of virus infection, conceivably by hampering the short fiber interaction with its cellular partner (Figure 5). This suggests an essential functional role in virus cell entry for the interaction of short fiber of enteric Ads with ParAd41, most probably after the initial step of virus attachment. In cultured cells, ParAd41 is localized in internal membranes including the nuclear membrane. We have demonstrated that in the cytoplasm ParAd41 overlaps with tubulin, a major component of the cytoskeleton, and is able to associate with the mitotic spindle. Furthermore, it overlaps with COPs, proteins circulating between the ER and the Golgi apparatus that are implicated in endocytosis. Interestingly, ParAd41 colocalizes also with lamin B, an integral membrane protein of inner nuclear membrane. These localization results suggest that ParAd41, through its ability to associate with enteric Ad short fiber, might be a protein that, using the microtubules for shuffling between the cytoplasmic and the nuclear membrane, promotes virus penetration to the cytoplasm and then its attachment to the nuclear membrane, aiding in viral DNA translocation to the nucleus.

Throughout this work, we used Caco-2 cells, a human colon cancer cell line unique in its ability to differentiate in vitro into a mature enterocyte-like cell type connected by tight junctions [23]. Assuming that the interaction of enteric Ad with ParAd41 is necessary for virus infection, our results concerning the effect of Caco-2 differentiation status on recombinant Ad40 infection (Figure 6) might suggest that the differentiated Caco- 2 cells contain more ParAd41 protein. Indeed, our confocal microscopy images might indicate this (see Figure 4(c) and compare red stain for ParAd41 in differentiated and un-differentiated Caco2), but more detailed comparative studies using different protein assessment techniques are required to state this unequivocally. Also, since it is known that expression pattern changes during cell differentiation [27], it would be of interest to estimate the amount of ParAd41 protein in different kinds of GI-derived cells and tissues.

The reasons for which the enteric Ads are able to infect the human gut are probably multifold. We have previously demonstrated that Ad41 infectivity is not diminished by acid exposure, a condition limiting the infectivity of the respiratory Ad [26]. This feature can be attributed to a large extent to the global basic charge of enteric Ad virions and to the stability of Ad41 fibers, with the Ad41 long fiber (but not the Ad5 fiber) still able to interact with CAR after exposure to acid. Both Ad41 fibers remained trimeric and survived well exposure to acid and proteolytic treatment, showing unusual stability under conditions simulating the GI milieu (op. cit.). Furthermore, upon exposure to $\mathrm{pH}$ shock, the respiratory Ad2 loses its ability to interact with lipids, while enteric Ad41 still binds to the major phospholipids of gastric and intestine mucus. The data presented in the present study expand our understanding of enteric Ad tropism. It is conceivable that after initial Ad41 attachment to CAR, the interaction of short fiber with ParAd41, localized in the intracellular membranes and in the nuclear envelope, mediates virus endocytosis and its attachment to the nuclear membrane prior to injection of viral DNA to the nucleus, thus enabling infection with enteric Ad.

Enteric adenovirus infection is a common cause of infantile diarrhea, accompanied by vomiting, abdominal pain, low-grade fever, and some dehydration [28], and there is no vaccine or prophylaxis known. Identification of the ParAd41 protein mediating the role of short fiber in the enteric adenovirus tropism may have some ramifications in the elaboration of specific antiviral treatments.

\section{Abbreviations}

aa: Amino acids

Ad: Adenovirus

AD: Activating domain of GAL4

BD: Binding domain of GAL4

CAR: Coxsackie adenovirus receptor

CBB: Coomassie brilliant blue

DF: Dodecahedron fiber, virus-like particle made of 12 Ad pentons

DPPC: Dipalmitoylphosphatidylcholine

DPPG: Dipalmitoylphosphatidylglycerol

ER: Endoplasmic reticulum

FBS: Fetal bovine serum

F5: $\quad$ Ad5 fiber protein

GI: Gastrointestinal tract

HLF41: Head domain of the Ad41 long fiber

HSF41: Head domain of the Ad41 short fiber

LP41: Long penton, complex of $\mathrm{Pb}$ with long fiber

MOI: Multiplicity of infection

$\mathrm{Pb}$ : Penton base

PC: Phosphatidylcholine

PE: $\quad$ Phosphatidylethanolamine 
PG: Phosphatidylglycerol

SP41: Short penton, complex of $\mathrm{Pb}$ with short fiber.

\section{Acknowledgments}

A.L.Favier was supported in part by a fellowship from Association pour la Recherche contre le Cancer (ARC). R.Grzela was supported in part by the NATO CLG grant. The authors are indebted to Qing-Hua Zhang (Shanghai Institute of Hematology, China) for the clone CBFBQE02 and to M. Havenga (Crucell Holland) for the recombinant Ad5 containing long or short Ad40 fiber (Ad5.LF40Luc and Ad5.SF40Luc). They are grateful to Bernard Dublet for the MS analysis and to Halina Sierakowska for thoughtful reading the paper.

\section{References}

[1] L. Philipson, K. Lonberg-Holm, and U. Pettersson, "Virusreceptor interaction in an adenovirus system," Journal of Virology, vol. 2, no. 10, pp. 1064-1075, 1968.

[2] L. J. Henry, D. Xia, M. E. Wilke, J. Deisenhofer, and R. D. Gerard, "Characterization of the knob domain of the adenovirus type 5 fiber protein expressed in Escherichia coli," Journal of Virology, vol. 68, no. 8, pp. 5239-5246, 1994.

[3] N. Louis, P. Fender, A. Barge, P. Kitts, and J. Chroboczek, "Cell-binding domain of adenovirus serotype 2 fiber," Journal of Virology, vol. 68, no. 6, pp. 4104-4106, 1994.

[4] P. W. Roelvink, A. Lizonova, J. G. M. Lee et al., "The coxsackievirus-adenovirus receptor protein can function as a cellular attachment protein for adenovirus serotypes from subgroups A, C, D, E, and F," Journal of Virology, vol. 72, no. 10, pp. 7909-7915, 1998.

[5] N. Arnberg, K. Edlund, A. H. Kidd, and G. Wadell, "Adenovirus type 37 uses sialic acid as a cellular receptor," Journal of Virology, vol. 74, no. 1, pp. 42-48, 2000.

[6] S. Tuve, H. Wang, C. Ware et al., "A new group B adenovirus receptor is expressed at high levels on human stem and tumor cells," Journal of Virology, vol. 80, no. 24, pp. 12109-12120, 2006.

[7] H. Wang, Z. Y. Li, Y. Liu et al., "Desmoglein 2 is a receptor for adenovirus serotypes 3, 7, 11 and 14," Nature Medicine, vol. 17, no. 1, pp. 96-104, 2011.

[8] P. A. Jacobsson, M. E. Johansson, and G. Wadell, "Identification of an enteric adenovirus by immunoelectroosmophoresis (IEOP) technique," Journal of Medical Virology, vol. 3, no. 4, pp. 307-312, 1979.

[9] I. Uhnoo, G. Wadell, L. Svensson, and M. E. Johansson, "Importance of enteric adenoviruses 40 and 41 in acute gastroenteritis in infants and young children," Journal of Clinical Microbiology, vol. 20, no. 3, pp. 365-372, 1984.

[10] A. L. Favier, G. Schoehn, M. Jaquinod, C. Harsi, and J. Chroboczek, "Structural studies of human enteric adenovirus type 41," Virology, vol. 293, no. 1, pp. 75-85, 2002.

[11] C. T. Tiemessen and A. H. Kidd, "Adenovirus type 40 and 41 growth in vitro: host range diversity reflected by differences in patterns of DNA replication," Journal of Virology, vol. 68, no. 2, pp. 1239-1244, 1994.

[12] J. Chroboczek, E. Gout, A. L. Favier, and R. Galinier, "Novel partner proteins of adenovirus penton," Current Topics in Microbiology and Immunology, vol. 272, pp. 37-55, 2003.

[13] A. Galanis, S. H. Yang, and A. D. Sharrocks, "Selective targeting of MAPKs to the ETS domain transcription factor SAP-1," Journal of Biological Chemistry, vol. 276, no. 2, pp. 965-973, 2001.

[14] W. P. Russ and D. M. Engelman, "The GxxxG motif: a framework for transmembrane helix-helix association," Journal of Molecular Biology, vol. 296, no. 3, pp. 911-919, 2000.

[15] S. Takada, C. G. Wilkerson, K. I. Wakabayashi, R. Kamiya, and G. B. Witman, "The outer dynein arm-docking complex: composition and characterization of a subunit (Oda1) necessary for outer arm assembly," Molecular Biology of the Cell, vol. 13, no. 3, pp. 1015-1029, 2002.

[16] D. M. Casey, K. Inaba, G. J. Pazour et al., "DC3, the 21-kDa subunit of the outer dynein arm-docking complex (ODA-DC), is a novel EF-hand protein important for assembly of both the outer arm and the ODA-DC," Molecular Biology of the Cell, vol. 14, no. 9, pp. 3650-3663, 2003.

[17] A. Hozumi, Y. Satouh, Y. Makino et al., "Molecular characterization of Ciona sperm outer arm dynein reveals multiple components related to outer arm docking complex protein 2," Cell Motility and the Cytoskeleton, vol. 63, no. 10, pp. 591-603, 2006.

[18] A. Spang, "On vesicle formation and tethering in the ER-Golgi shuttle," Current Opinion in Cell Biology, vol. 21, no. 4, pp. 531-536, 2009.

[19] S. Vlcek, T. Dechat, and R. Foisner, "Nuclear envelope and nuclear matrix: interactions and dynamics," Cellular and Molecular Life Sciences, vol. 58, no. 12-13, pp. 1758-1765, 2001.

[20] A. N. Giberson, A. R. Davidson, and R. J. Parks, "Chromatin structure of adenovirus DNA throughout infection," Nucleic Acids Research, vol. 40, no. 6, pp. 2369-2376, 2012.

[21] R. Persson, C. Wohlfart, U. Svensson, and E. Everitt, "Virusreceptor interaction in the adenovirus system: characterization of the positive cooperative binding of virions on HeLa cells," Journal of Virology, vol. 53, no. 4, pp. 92-97, 1985.

[22] T. J. Wickham, P. Mathias, D. A. Cheresh, and G. R. Nemerow, "Integrins $\alpha(\mathrm{v}) \beta 3$ and $\alpha(\mathrm{v}) \beta 5$ promote adenovirus internalization but not virus attachment," Cell, vol. 73, no. 2, pp. 309-319, 1993.

[23] D. Louvard, M. Kedinger, and H. P. Hauri, “The differentiating intestinal epithelial cell: establishment and maintenance of functions through interactions between cellular structures," Annual Review of Cell Biology, vol. 8, pp. 157-195, 1992.

[24] P. Mathias, T. Wickham, M. Moore, and G. Nemerow, "Multiple adenovirus serotypes use $\alpha \mathrm{v}$ integrins for infection," Journal of Virology, vol. 68, no. 10, pp. 6811-6814, 1994.

[25] B. Albinsson and A. H. Kidd, "Adenovirus type 41 lacks an RGD $\alpha(\mathrm{v})$-integrin binding motif on the penton base and undergoes delayed uptake in A549 cells," Virus Research, vol. 64, no. 2, pp. 125-136, 1999.

[26] A. L. Favier, W. P. Burmeister, and J. Chroboczek, "Unique physicochemical properties of human enteric Ad41 responsible for its survival and replication in the gastrointestinal tract," Virology, vol. 322, no. 1, pp. 93-104, 2004. 
[27] R. Gauthier, C. Harnois, J. F. Drolet, J. C. Reed, A. Vézina, and P. H. Vachon, "Human intestinal epithelial cell survival: differentiation state-specific control mechanisms," American Journal of Physiology, vol. 280, no. 6, pp. C1540-C1554, 2001.

[28] K. Jarecki-Khan, S. R. Tzipori, and L. E. Unicomb, "Enteric adenovirus infection among infants with diarrhea in rural Bangladesh," Journal of Clinical Microbiology, vol. 31, no. 3, pp. 484-489, 1993. 

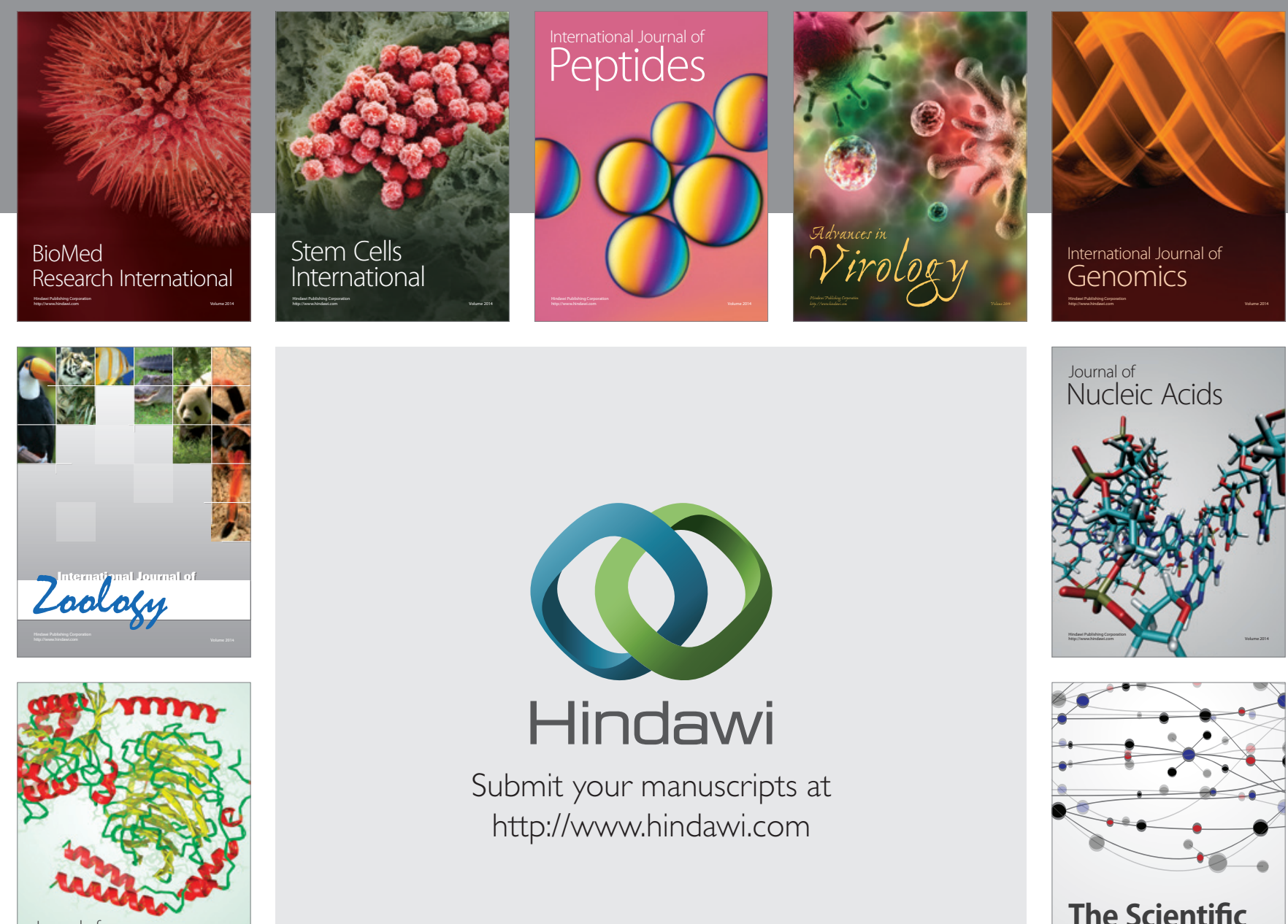

Submit your manuscripts at

http://www.hindawi.com

Journal of
Signal Transduction
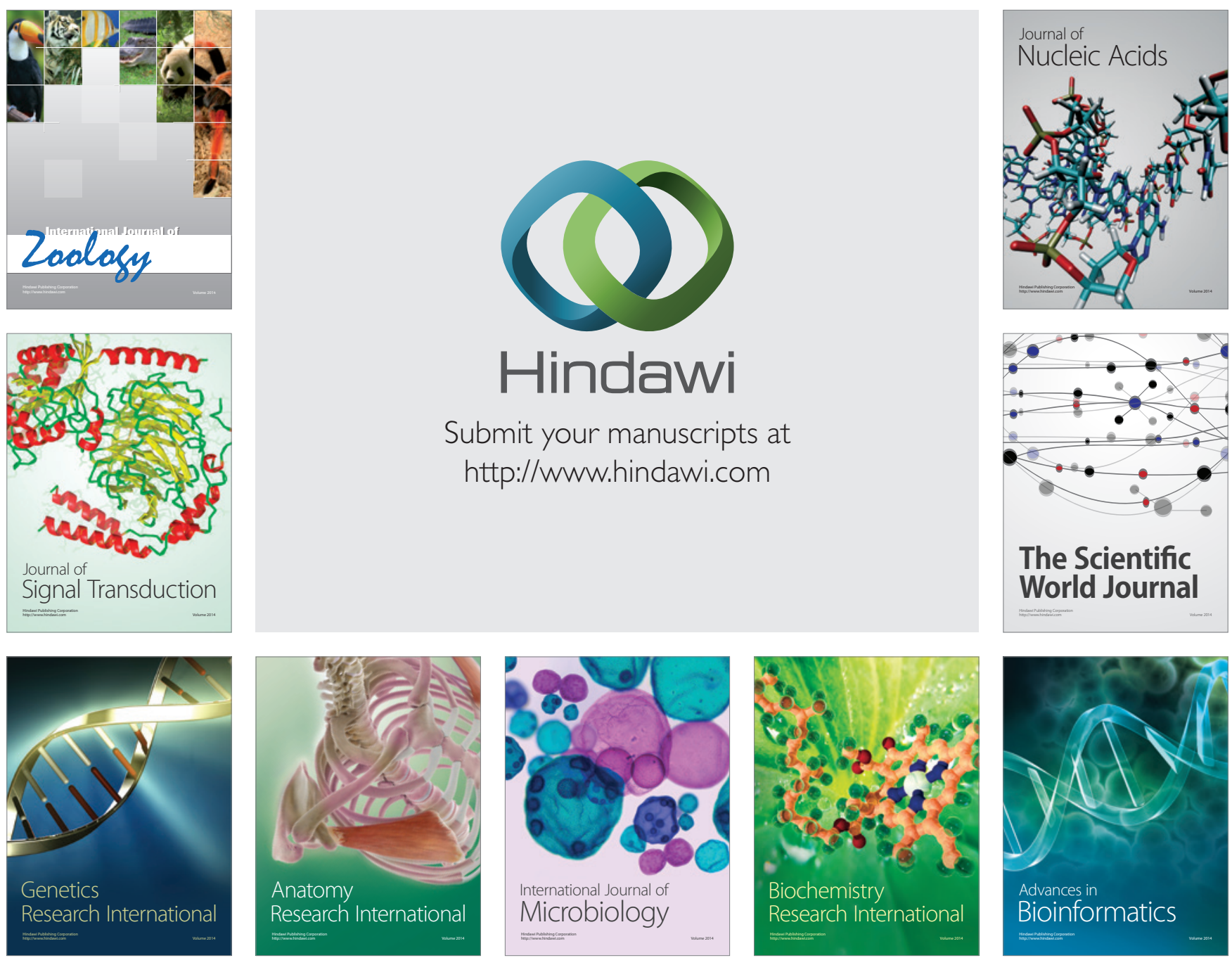

The Scientific World Journal
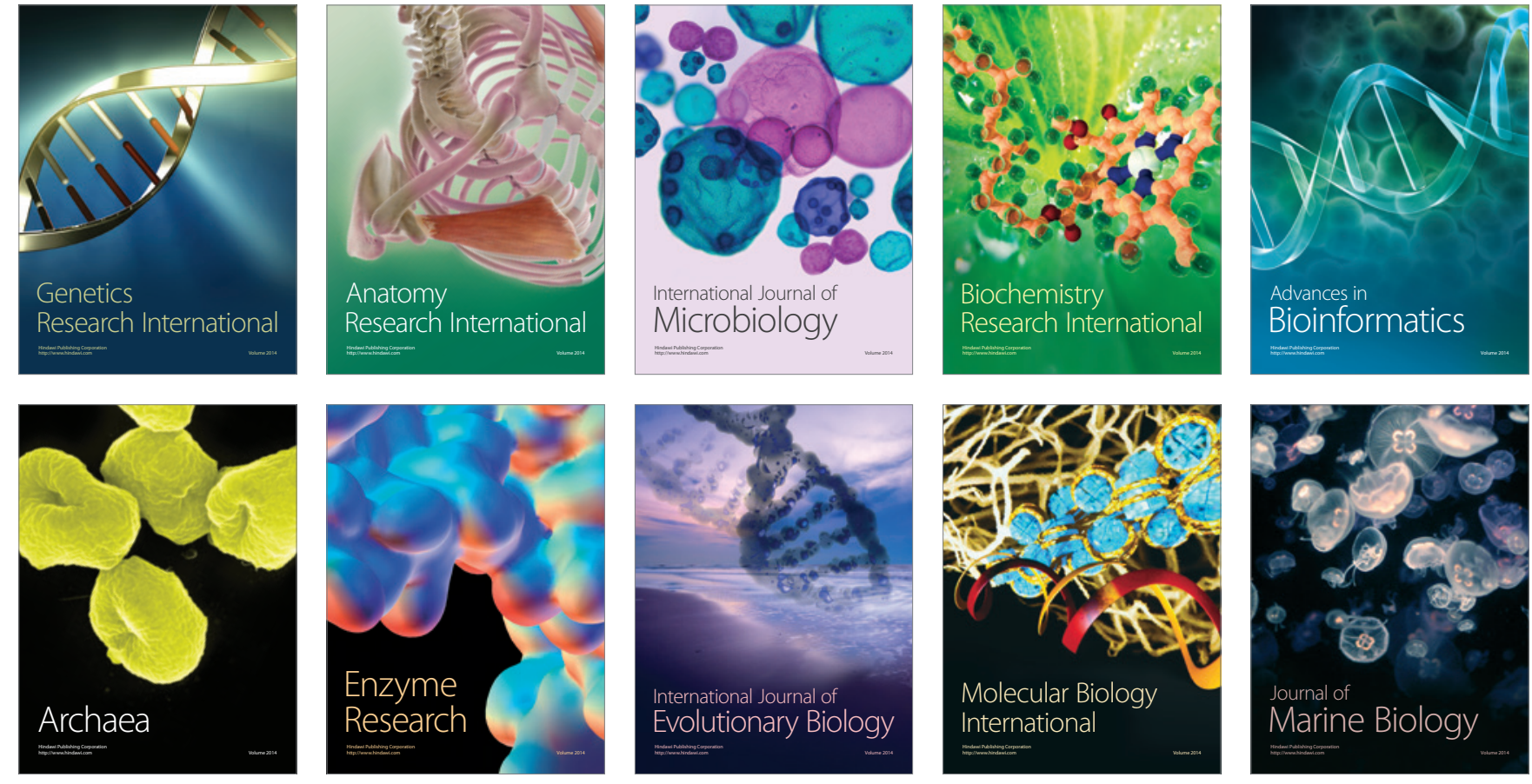